\title{
过渡金属催化的有机硼试剂对亚胺的不对称加成研究进展
}

\author{
陈 雕 徐明华* \\ (中国科学院上海药物研究所 新药研究国家重点实验室 上海 201203)
}

\begin{abstract}
摘要 手性胺是有机合成中一类非常重要的合成砌块, 在天然产物、生物活性分子及药物分子中广泛存在, 因此发展 高效的构建手性胺类化合物的方法，一直都是合成有机化学家们关注的重点. 有机硼试剂近年来以其低毒、稳定、易 得等优点逐渐受到合成化学家的青睐, 被越来越多地用于过渡金属催化的反应中. 本文综述了近十多年来基于手性辅 剂及手性催化策略的过渡金属催化的有机硼试剂对亚胺的不对称加成研究进展, 着重探讨了各种手性配体在反应中的 应用以及 $\alpha$-手性胺类化合物的立体选择性构建.
\end{abstract}

关键词 不对称合成; 手性胺; 金属催化; 不对称加成; 有机硼试剂

\section{Transition Metal-Catalyzed Asymmetric Addition of Organoboron Reagents to Imines}

\author{
Chen, Diao $\quad \mathrm{Xu}$, Ming-Hua* \\ (State Key Laboratory of Drug Research, Shanghai Institute of Materia Medica, \\ Chinese Academy of Sciences, Shanghai 201203)
}

\begin{abstract}
Chiral amines are important building blocks in organic synthesis, they also present in numerous natural products, biologically active compounds and pharmaceutical agents. In recent years, the use of various organoboron reagents in transition metal-catalyzed reactions has attracted considerable attentions because of their ready avilibility, low toxicity, good air and moisture stability as well as high functional group compatibility. This review summarizes the remarkable progress and advances in transition metal-catalyzed asymmetric addition of organoboron reagents to imines over the past few years, providing an overview of the recent achievements in stereoselective synthesis of $\alpha$-chiral amines by using chiral auxiliary or chiral catalysis strategies. At the present time, rhodium-based asymmetric catalysis has proven to be the most efficient and reliable approach to furnish highly optically active $\alpha$-chiral amines. Varieties of chiral ligands including monophosphines, biphosphines, amidomonophosphanes, phosphoramidites, phosphites, dienes, sulfur-olefins, phosphorus-olefins have showed the great potential in many asymmetric additions of organoboron reagents to imines, enabling the access of both secondary and tertiary $\alpha$-chiral amines with good to excellent enantioselectivities. On the other hand, important progress has been made in developing effective palladium catalysts mainly based on chiral pyridine-oxazoline and phosphine-oxazoline ligands. However, future studies in this area towards the objective of developing more efficient, practical and general methods remain challenging.

Keywords asymmetric synthesis; chiral amine; metal catalysis; asymmetric addition; organoboron
\end{abstract}

手性胺结构广泛存在于各种天然产物、生物活性分 子及药物分子中 ${ }^{[1]}$, 因此发展高效的构建手性胺类化合 物的方法, 一直都是合成有机化学家们关注的重点. 近 几十年来, 随着手性技术的发展, 利用不对称反应实现 手性胺化合物的高立体选择性合成取得了重要进展. 对 于 $\alpha$-手性胺类化合物的制备, 依据合成策略, 主要可以 概括为以下三类: (1)不对称氨基化 ${ }^{[2]}$; (2)前手性烯胺、亚
胺的不对称还原 $(\text { 氢化 })^{[3]} ;(3)$ 有机富电子试剂 ${ }^{[4 a, 4 b]}$ 或者 有机金属试剂 ${ }^{[4 c \sim 4 f]}$ 对亚胺的不对称加成(图 1). 其中, 通过不对称还原或氢化反应策略只能得到含二取代和 三取代碳手性中心的 $\alpha$-手性胺，而不对称氨基化和不对 称加成策略则可以合成含季碳手性中心的手性胺类化 合物.

虽然利用有机金属试剂对亚胺进行不对称加成是

* Corresponding author. E-mail: xumh@simm.ac.cn
Received April 12, 2017; revised May 2, 2017; published online May 10, 2017.

Project supported by the National Natural Science Foundation of China (Nos. 21325209, 21472205) and the Program of Shanghai Academic Research Leaders (No. 14XD1404400).

国家自然科学基金(Nos. 21325209, 21472205)、上海市优秀学术带头人计划(No. 14XD1404400)资助项目. 
获得高光学纯度手性胺的有效方法, 但传统的有机金属 试剂大都存在一些固有的缺点或不足, 例如价格昂贵、

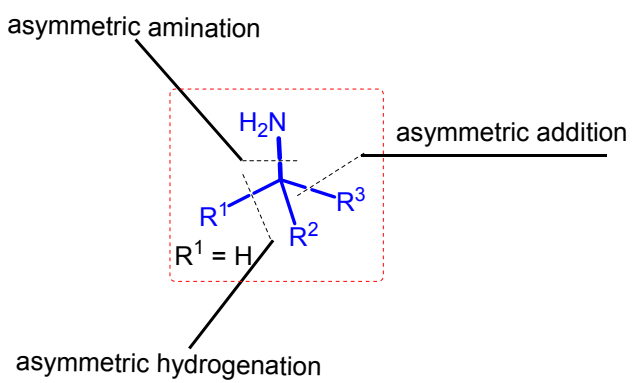

图 $1 \alpha$-手性胺合成策略

Figure 1 Synthetic strategies for $\alpha$-chiral amine

毒性较大、对水和空气敏感, 甚至需要现场制备, 不利 操作等. 近年来, 有机硼试剂由于低毒、稳定、可以直 接从市场购买等优点，在有机合成中的应用越来越受到 人们的青睐 ${ }^{[5]}$. 在合适的过渡金属如铑、钯等催化下，有 机硼试剂通过转金属化生成相应的有机金属活性物种 参与反应. 本文主要讨论在过去的十来年里, 利用有机 嗍试剂对亚胺进行不对称加成制备 $\alpha$-手性胺类化合物 取得的结果, 分醛亚胺和酮亚胺两个部分展开, 分别描 述基于手性辅剂策略和手性金属配合物催化策略的研 究进展.

\section{1 醛亚胺的不对称加成}

手性二芳基甲胺及手性 $\alpha$-芳基甘氨酸结构是很多 生物活性分子及药物分子的重要组成部分, 如: 组胺 $\mathrm{H}_{1}$ 受体拮抗剂盐酸西替利嗪, 以及非肽类选择性阿片受体 激动剂 SNC80 具有手性二芳基甲胺的结构骨架 ${ }^{[1 \mathrm{c}]}$; 抗 生素 Cefprozil ${ }^{[1 \mathrm{dd}]}$ 具有手性 $\alpha$-芳基甘氨酸的结构骨架(图
2). 利用过渡金属催化的嗍试剂对芳基酫亚胺或者醛酸 酯亚胺的不对称加成是合成这两类化合物的一个非常 有效的方法.<smiles>O=C(O)COCCN1CCN([C@H](c2ccccc2)c2ccc(Cl)cc2)CC1</smiles><smiles>C=CCN1CC(C)N(C(c2ccc(C(=O)NCC)cc2)c2cccc(OC)c2)C[C@H]1C</smiles>

(S)-Cetirizine<smiles>C/C=C/C1=C(C(=O)O)N2C(=O)C(NC(=O)C(N)c3ccc(O)cc3)[C@H]2SC1</smiles>

Cefprozil

图 2 含 $\alpha$-手性胺骨架的生物活性分子

Figure 2 Bioactive compounds with $\alpha$-chiral amine motif

\section{1 辅剂策略}

Ellman 小组 ${ }^{[6]}$ 在 2005 年报道了铑催化下膦配体促 进的芳基硼酸对手性 $N$-叔丁基亚磺酰亚胺的不对称加 成反应(Eq. 1). 在最初的研究中, 作者发现反应收率与 反应物浓度成反比，而且有较多副产物苯生成，推测是 苯硼酸转金属化后的芳基铑物种直接质子化，导致亚胺 加成反应收率不高. 基于这个分析, 通过在 $6 \mathrm{~h}$ 内缓慢 加入苯硼酸将其浓度维持在一个较低的水平，果然将反 应产率提高到了 $96 \%$. 在底物适应性考查中, 发现无论 是富电子还是缺电子硼酸都能取得较好结果, 该反应体 系还适用于脂肪亚胺的加成. 此外, 该课题组还进一步

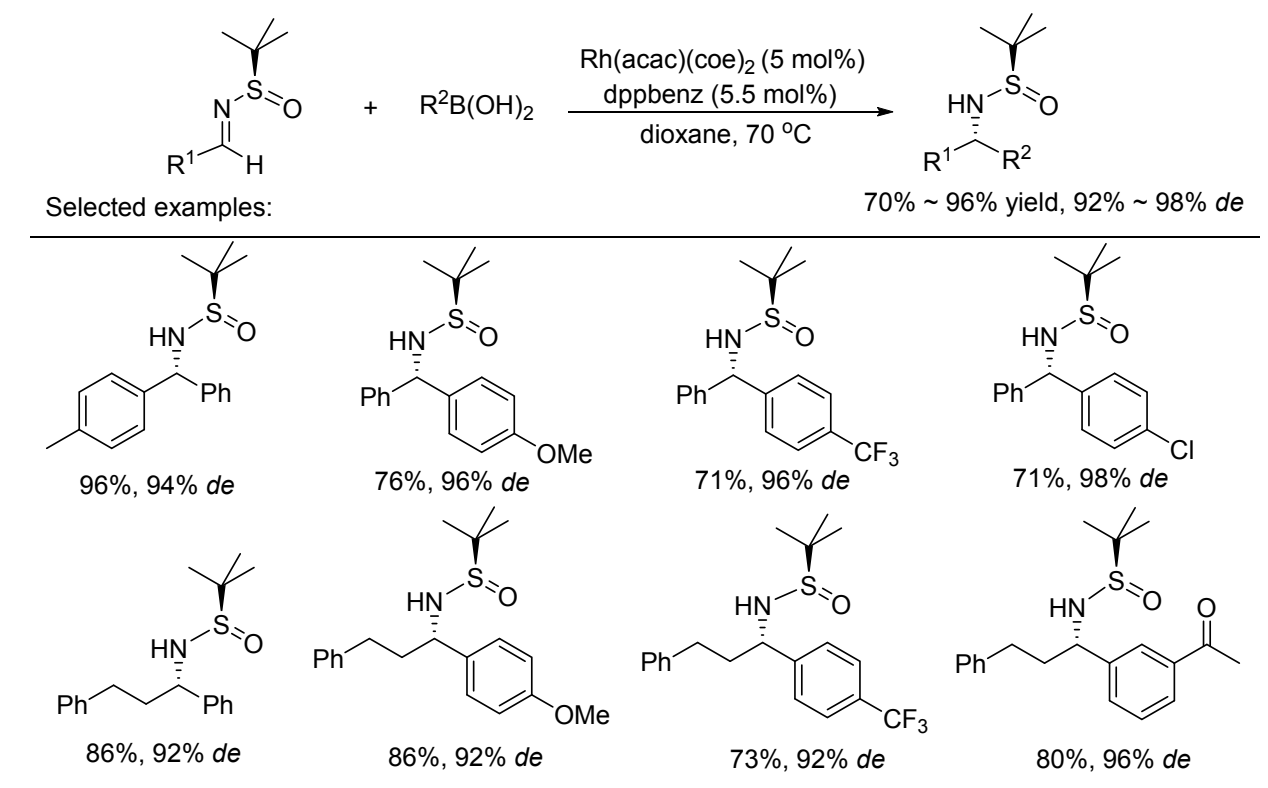


实现了以醛为起始原料先形成亚胺再进行不对称芳基 化的一锅煮反应, 同样取得了很好的收率以及立体选择 性.

同年, Batey 等 ${ }^{[7]}$ 也利用类似策略, 发展了一套新的 反应体系用于芳基硼酸对手性 $N$-叔丁亚磺酰醛亚胺的 不对称加成反应. 相比 Ellman 小组的反应体系, 不需要 外加膦配体, 也无需缓慢加入嗍酸, 反应在室温下即可 进行并能取得较好的收率和同样优秀的非对映选择性

(Eq. 2).

2006 年, Ellman 小组 ${ }^{[8]}$ 又报道了一价铑催化下芳基 碍酸对乙醛酸酯亚胺的不对称加成反应, 用于手性 $\alpha$-芳 基甘氨酸的合成，取得了 $61 \% \sim 90 \%$ 收率，96\% 98\% de. 研究发现, 嗍酸芳环上取代基的电性变化对反应收 率及立体选择性的影响不大. 所得产物在不同的反应条
件下可以选择性地脱除亚磺酰基或者水解酯基，在 $\mathrm{NaBH}_{4}$ 的条件下经还原得到手性 $\beta$-氨基醇，同时可以方 便地与亮氨酸甲酯发生缩合反应得到二肽 (Eq. 3, Scheme 1).

基于同样的辅剂诱导策略, Ellman 等 ${ }^{[9]}$ 随后又实现 了铑催化下烯基氟硼酸钾对芳香醛亚胺及脂肪醛亚胺 的不对称加成, 合成了一系列高光学纯度的 $\alpha$-取代烯丙 胺. 反应的底物适应性较广，各种取代的烯基氟硼酸钾 均能取得很好结果. 当反应规模扩大至 $10 \mathrm{mmol}$ 时，仍 然能取得同样的收率及 $d e$ 值(Eq. 4).

由于烯基氟硼酸钾在反应的过程中会涉及到自身 脱嗍、氧化及多聚化等副反应，因此找到另外一种更加 稳定的嗍试剂可能会提高反应收率. 确实, 当用 BMIDA 嘲酸酯作为硼试剂时，相应的不对称烯基化反应可以取

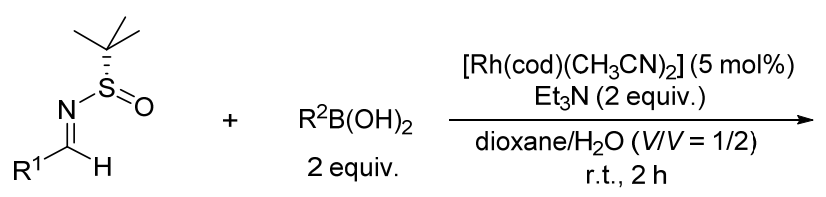

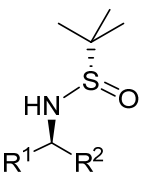

$44 \% \sim 99 \%$ yield, $83 \% \sim 97 \%$ de

Selected examples:

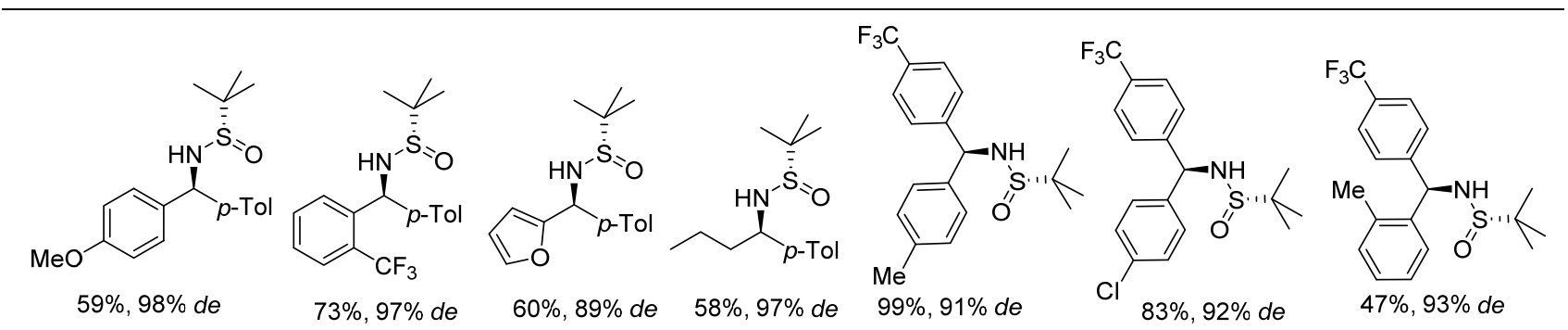<smiles>COC(=O)/C=N/[S@](=O)C(C)(C)C</smiles>

$$
61 \% \sim 90 \% \text { yield, } 96 \% \sim 98 \% \text { de }
$$<smiles>COC(=O)[C@H](CC(C)C)NC(=O)[C@H](N[S@](=O)C(C)(C)C)c1ccc(Cl)cc1</smiles>

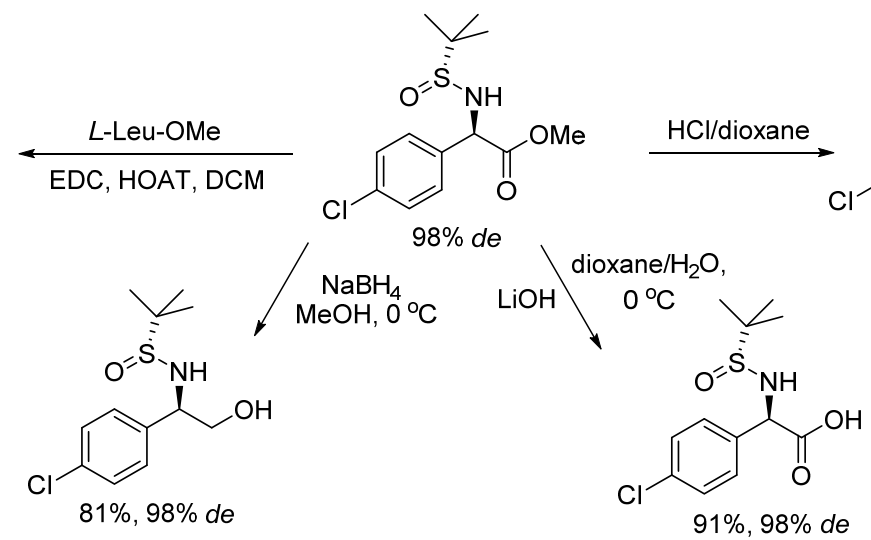

图式 1 芳基甘氨酸酯产物的衍生化

Scheme 1 Derivation of the arylglycine ester product 
<smiles>[R]C=N[R](=O)C(C)(C)C</smiles>

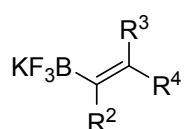
$[\mathrm{Rh}(\operatorname{cod})(\mathrm{OH})]_{2}(2.5 \mathrm{~mol} \%)$ dppbenz $(5.0$ mol\%)
$\mathrm{NEt}_{3}$ (2 equiv.) $\mathrm{H}_{2} \mathrm{O} / \mathrm{DMF}(\mathrm{V} / \mathrm{V}=3 / 2), 60^{\circ} \mathrm{C}$

Selected examples:

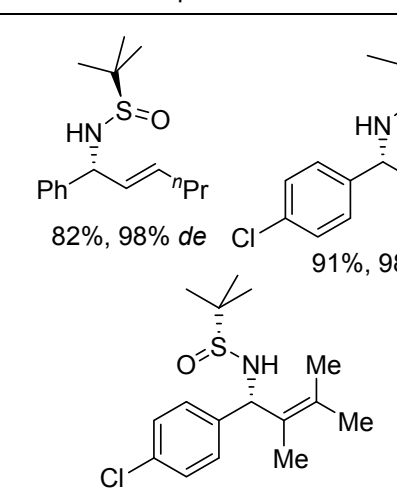

$75 \%, 98 \%$ de<smiles>CCCC=CC(CCl)NS(=O)C(C)(C)C</smiles>

$64 \%, 96 \%$ de

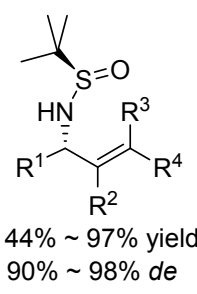

(4)

$90 \% \sim 98 \%$ de<smiles>CNC(=O)NNC(=O)C(C)(C)C</smiles><smiles>CC=CCc1ccc(Oc2ccccc2)cc1</smiles>

Cl $70 \%, 96 \%$ de<smiles>CCCC=CC(CCc1ccccc1)NC(=O)C(C)(C)C</smiles>

$78 \%, 98 \%$ de<smiles>CC(C)(C)C(=O)N[C@@H](CCc1ccccc1)C(=O)Nc1ccccc1</smiles>

$97 \%, 92 \%$ de

得最高 98\%收率和 $98 \% d e^{[10]}$. 相比较烯基氟硼酸钾的 结果, 利用 BMIDA 硼酯试剂的每个实施例的收率及 $d e$ 值都更好; 对于收率不理想的多取代的烯基硼试剂及缺 电子芳基烯基硼试剂参与的反应, 尤其可以取得较高收 率(Eq. 5).

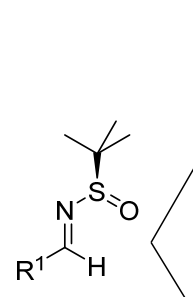<smiles></smiles>

$[\mathrm{Rh}(\operatorname{cod})(\mathrm{OH})]_{2}(2.5 \mathrm{~mol} \%)$ dppbenz ( $5.0 \mathrm{~mol} \%)$ up to $98 \%$ yield, $98 \%$ de $\mathrm{K}_{3} \mathrm{PO}_{4}$ (2 equiv.)

$\mathrm{H}_{2} \mathrm{O} /$ dioxane $(\mathrm{VIV}=3 / 2), 60^{\circ} \mathrm{C}$<smiles></smiles>

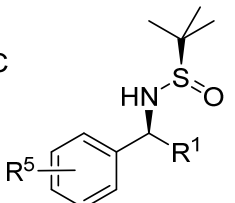

up to $89 \%$ yield, $96 \%$ de

BMIDA =

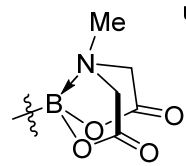

以该不对称烯基化反应为关键步骤, Ellman 小组 ${ }^{[1]}$ 通过 6 步 27\%总收率成功实现了天然产物(一)-Aurantioclavine 的高效不对称合成, 而此前文献报道需要 13 步 反应且总收率 $<1 \%$ (Scheme 2).
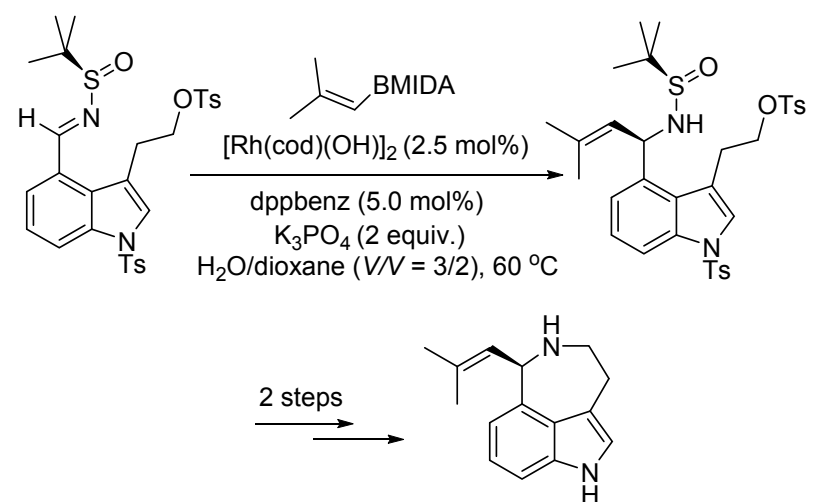

(-)-Aurantioclavine $27 \%$ overall yield

图式 2 (-)-Aurantioclavine 的高效不对称合成

Scheme 2 Efficient asymmetric synthesis of (-)-aurantioclavine

不同于 Ellman 等 ${ }^{[8]}$ 的铑催化方法, $\mathrm{Lu}$ 小组 ${ }^{[12]}$ 在 2007 年报道了阳离子型钯物种催化下的芳基嗍酸对乙 醛酸酯亚胺的不对称加成反应，也成功实现了手性 $\alpha$-芳 基甘氨酸的不对称合成. 芳基钯物种相对铑物种来说亲 核性更弱，所以其大多用于碳-碳键及碳一杂键生成的偶 联反应中. 相对于中性钯物种，阳离子钯中心有空置的 配位点，同时具有更 “硬” 的配位性质，所以其在反应 中可以起到路易斯酸的作用从而活化亚胺以提高反应 收率(Eq. 6).

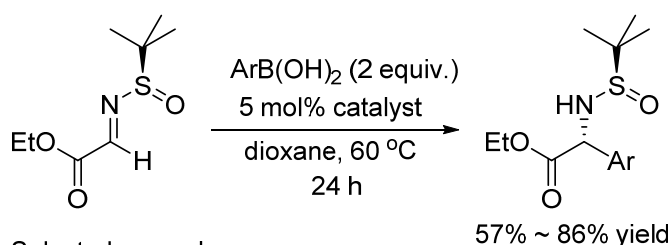

Selected examples: $\quad 57 \% \sim 86 \%$ yield

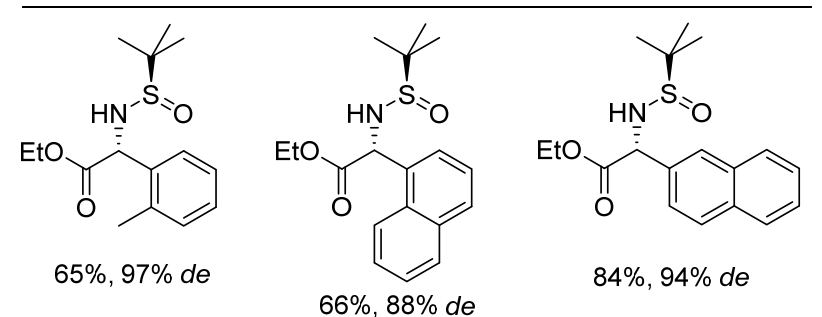

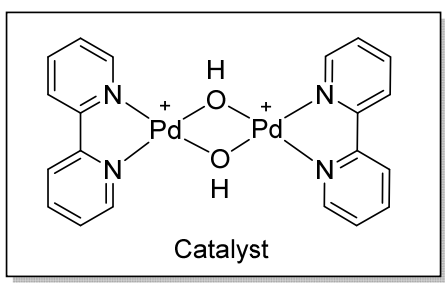

$62 \%, 88 \%$ de

\section{2 手性配体策略}

之前所述的辅剂策略其优势在于产物的叔丁亚磺 
酰基能在温和的反应条件下方便地脱除 ${ }^{[6,8]}$, 但缺点在 于需要当量的手性源, 不够经济. 因此通过合理设计手 性配体, 利用催化量的手性催化剂实现反应的对映选择 性控制, 相比辅剂策略而言原子经济性更好, 也是当前 合成化学发展的必然趋势.

\subsection{1 手性膦一酰胺配体}

2004 年, Tomioka 小组 ${ }^{[13]}$ 设计了一类基于 $L$-缬氨酸 骨架的膦一酰氨配体(L1a), 用于一价铑催化的芳基硼酐 对 $N$-Ts 醛亚胺的不对称加成反应. 这是最早的铑催化 的嗍试剂对亚胺加成的成功例子. 有意思的是, 反应适 用于位阻较大的芳香亚胺, 芳基邻位取代的亚胺及 1 -萗 亚胺可以取得最好的对映选择性, 而其它底物则结果并 不理想(Eq. 7).

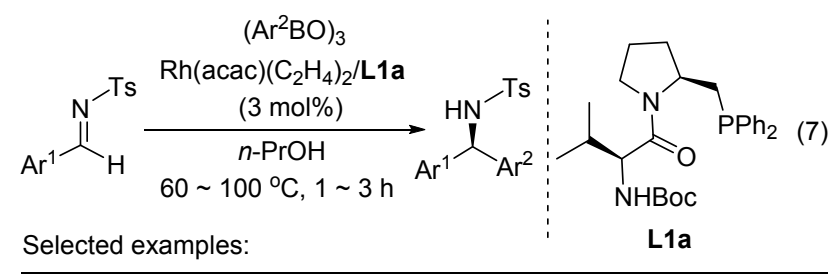

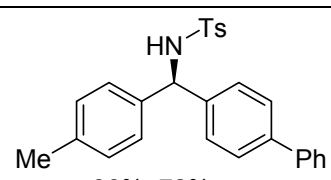

$86 \%, 72 \%$ ee<smiles>Cc1ccccc1C(NC(C)(F)F)c1ccc(-c2ccccc2)cc1</smiles>

$97 \%, 86 \%$ ee

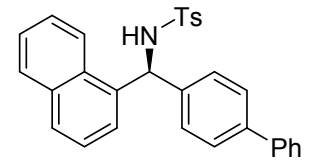

$88 \%, 92 \%$ ee<smiles>Cc1ccccc1[C@H](NS(C)(=O)=O)c1cccc(Cl)c1</smiles>

$99 \%, 94 \%$ ee
在进一步的研究中, 该小组 ${ }^{[14]}$ 发现增大配体中与 磷原子相连芳基的位阻有利于反应的立体选择性控制, 使用配体 L1b 可以明显提高产物的 $e e$ 值, 但由于催化 活性有一定程度的降低, 需要在反应体系中加入 $4 \AA$ 分 子篮来抑制反应时间延长导致的亚胺水解. 与之前的结 果相比, 这类改进的配体对底物的适应性较好, 除邻位 有位阻的芳基亚胺大都能取得较好的结果(Eq. 8). 膦酰 基保护基也可以在产物 $e e$ 值保持的情况下温和地脱除.

在对反应过渡态的思考方面 ${ }^{[15]}$, 作者认为转金属 化后的芳基优先处于磷原子的反位, 这样亚胺从酰基氧 的反位与铑配位, TS-1 中配体分子中磷原子上的苯基与 亚胺氮上的芳基膦酰基存在明显的位阻, 所以 TS-2 所 示为更有利的配位模式(Eq. 9). 这也解释了增加配体中 磷原子上取代基的位阻能提高反应的立体选择性.

之后, Tomioka 小组 ${ }^{[16]}$ 对该反应又进行了进一步的 条件优化, 发现选用三苯基硼烷作为亲核试剂, 可以将 反应时间缩短至最快 $1 \mathrm{~h}$, 从而有效地避免了亚胺水解. 反应普遍能取得良好的收率( $84 \% \sim 92 \%$ )和对映选择性
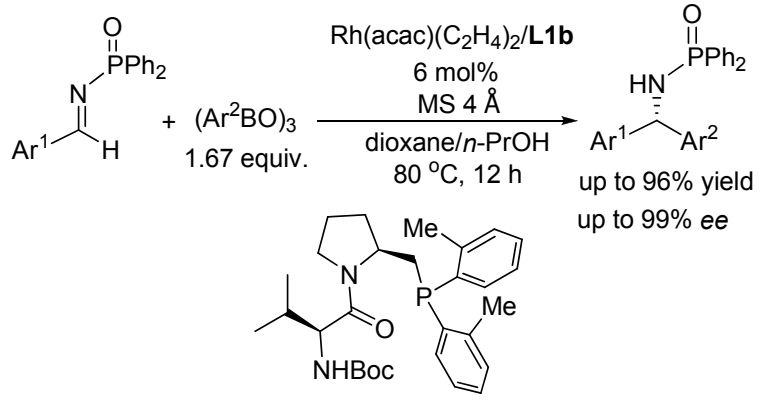

up to $99 \%$ ee

Select examples:

L1b<smiles>Cc1ccc(C(NP(=O)(c2ccccc2)c2ccccc2)c2ccccc2)cc1</smiles>

$96 \%, 98 \%$ ee<smiles>COc1cccc(C(NP(=O)(c2ccccc2)c2ccccc2)c2ccccc2)c1</smiles>

$88 \%, 95 \%$ ee<smiles>Cc1ccc([C@H](NP(=O)(c2ccccc2)c2ccccc2)c2ccc(-c3ccccc3)cc2)cc1</smiles>

$93 \%, 99 \%$ ee<smiles>O=[PH](N[C@H](c1ccc(Cl)cc1)c1ccc(-c2ccccc2)cc1)c1ccccc1</smiles>

$85 \%, 96 \%$ ee<smiles>Cc1ccc(C(NP(=O)(c2ccccc2)c2ccc3ccccc3c2)c2ccccc2)cc1</smiles>

$92 \%, 97 \%$ ee<smiles>O=[PH](N[C@H](c1ccc(-c2ccccc2)cc1)c1ccc(C(F)(F)F)cc1)c1ccccc1</smiles>

$83 \%, 90 \%$ ee<smiles>Cc1ccc(C(NP(=O)(c2ccccc2)c2ccccc2)c2ccco2)cc1</smiles>

$84 \%, 92 \%$ ee

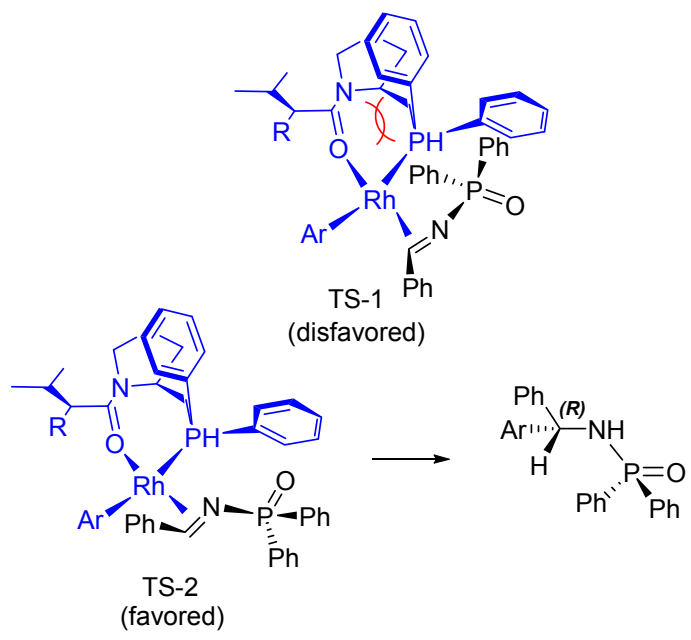

$(90 \% \sim 96 \%$ eе) (Eq. 10).<smiles>O=[PH+](/N=C/[Al])Pc1ccccc1</smiles>

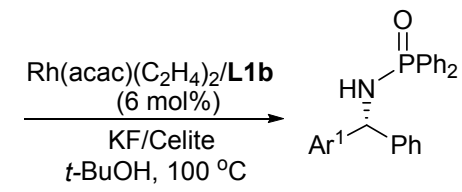
$90 \% \sim 96 \%$ ee 


\subsection{2 手性膦配体}

2005 年, Ellman 小组 ${ }^{[6]}$ 利用 $(R, R)$-DeguPHOS 作为手 性配体，实现了铑催化的芳基硼酸对苯甲醛膦酰亚胺的 不对称加成反应，取得了 $87 \%$ ～97\%的收率和 $88 \%$ $94 \%$ ee (Eq. 11).

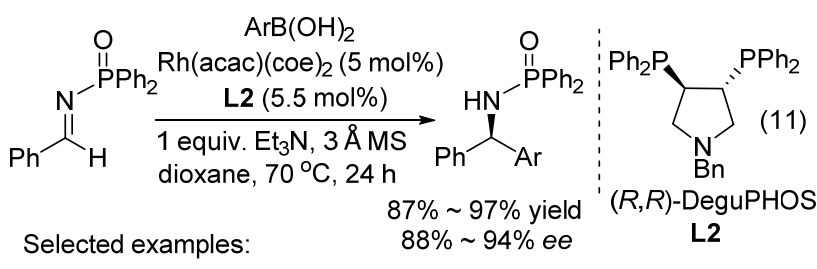<smiles>O=[PH](NC(c1ccccc1)c1ccc(Cl)cc1)c1ccccc1</smiles>

$97 \%, 94 \%$ ee<smiles>CC(=O)c1cccc(C(N[P+](=O)[O-])c2ccccc2)c1</smiles>

$93 \%, 88 \%$ ee

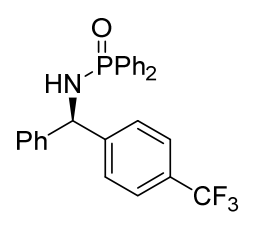

$87 \%, 88 \%$ ee
相比芳基亚胺, 脂肪亚胺由于很容易在酸性或碱性 条件下互变为烯胺以及发生自身缩合反应, 所以其不对 称芳基化反应往往更加挑战. 基于上述反应的催化体 系, Ellman 小组 ${ }^{[17]}$ 经过细致的研究, 成功实现了铑催化 下 DeguPhos 促进的芳基硼酸对脂肪醛亚胺的不对称加 成反应. 他们发现将配体与铑的比例提高到 $1.4: 1$, 可 以有效地提高反应的收率及立体选择性, 而且在原位形 成催化剂后加入硼酸, 保持 $90 \mathrm{~min}$ 后再加入亚胺就可以 有效地避免亚胺自身缩合. 反应的底物适应性较好, 各 种类型的脂肪亚胺都能在反应中给出良好的收率和对 映选择性(Eq. 12).

2006 年, Feringa, Minnaard 等 ${ }^{[18]}$ 报道了 $N, N$-二甲基 氨磺酰亚胺的不对称芳基化反应. 在最初的研究中, 发 现简单的 MonoPhos 与铑的配合物就能催化反应并取得 $82 \% e e$, 结合组合化学策略对配体进行大量篎选, 发现 对一甲氧基苯胺衍生的亚磷酰胺 $\mathbf{L 3}$ 是最好的配体. 在最 优条件下, 硼酸用量可以低至 1.3 equiv., 反应能取得 $72 \% \sim 98 \%$ 收率及 $82 \% \sim 95 \%$ 的对映选择性. 不足的是, 反应对亚胺底物及硼酸的电子性质和空间位阻相对敏 感, 有一定的局限性. 相比 Ts 基团, 产物胺基上的 $N, N-$ 二甲基氨磺酰基可以在微波反应条件下更方便地脱除 (Eq. 13).

同年, Zhou 等 ${ }^{[19]}$ 发现单亚磷酸酯类配体可以促进 一价铑催化的芳基硼酸对苯甲醛亚胺的不对称加成反 应(Eq. 14). 研究表明, 铑源的不同对反应结果影响很 大, 以 $[R h] / \mathbf{L} 4$ 配合物为催化剂, KF 为添加剂时反应可 以取得较高收率(56\% 85\%) 和对映选择性( $85 \%$ ～96\% $e e)$. 作者认为配体中手性螺环骨架所提供的较大的二 面角对反应的立体选择性起着决定性作用.

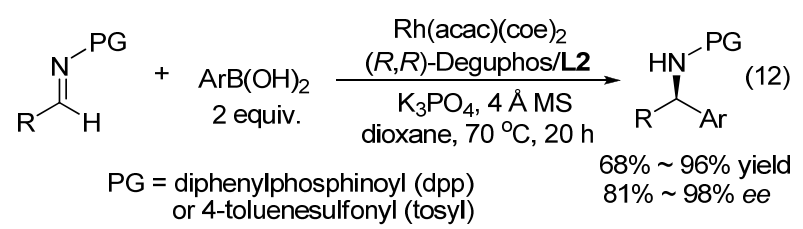

Selected examples:<smiles>CC(C)CC(N[13F])c1ccc(Cl)cc1</smiles><smiles>CCC[C@H](NP(=O)(c1ccccc1)c1ccc(Cl)cc1)c1ccc(F)cc1</smiles>

$80 \%, 90 \%$ ee

$89 \%, 86 \%$ ee

$75 \%, 84 \%$ ee<smiles>O=[PH](NC(c1ccc(Cl)cc1)C1CC1)c1ccccc1</smiles>

$79 \%, 95 \%$ ee<smiles>O=[PH](NC(CCc1ccccc1)c1ccc(C(F)(F)F)cc1)c1ccccc1</smiles>

$85 \%, 82 \%$ ee
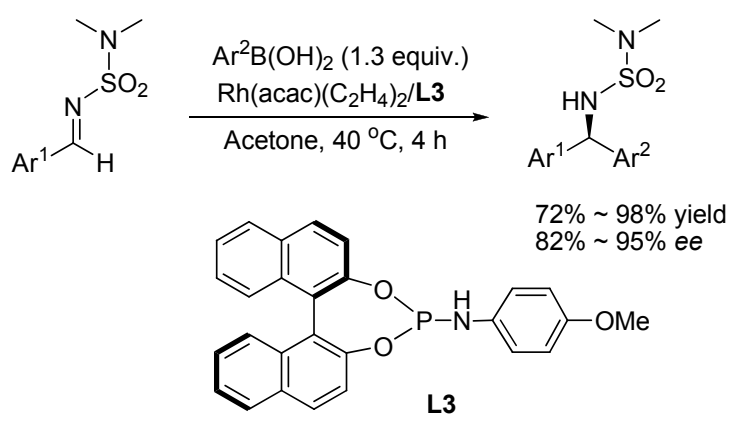

Select examples:

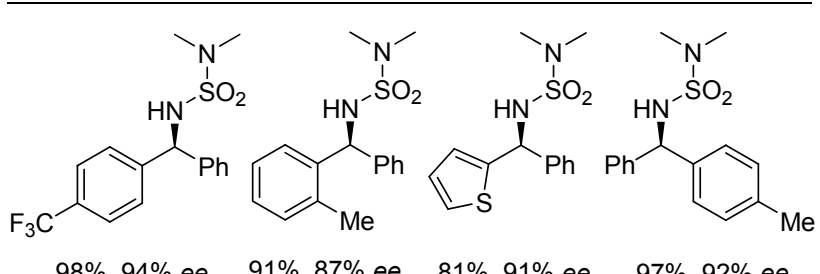

2009 年, Yamamoto 和 Miyaura 等 ${ }^{[20]}$ 设计了双齿亚膦 酰胺配体 L5, 研究了其在铑催化的芳基硼酸对 $N$-Ts 及 $N-\mathrm{Ns}$ 苯甲醛亚胺的不对称加成中的应用，反应可以取 得 $61 \% \sim 99 \%$ 的收率及 $18 \% \sim 99 \%$ 的对映选择性. 作 者认为反应可能存在一定的位阻需求，因为两个反应底 物中如果其中一个为不带任何取代基的苯环时通常只 能取得低于 $90 \%$ ee (Eq. 15). 


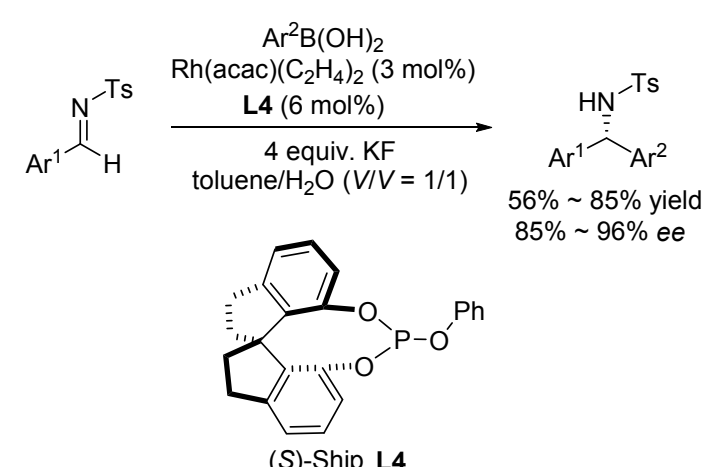

(S)-Ship L4

Selected examples:

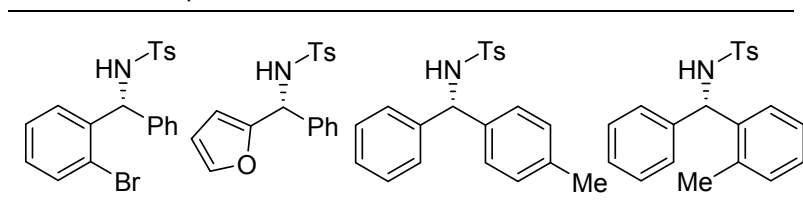

$76 \%, 93 \%$ ee $84 \%, 85 \%$ ee $75 \%, 92 \%$ ee

$65 \%, 93 \%$ ee

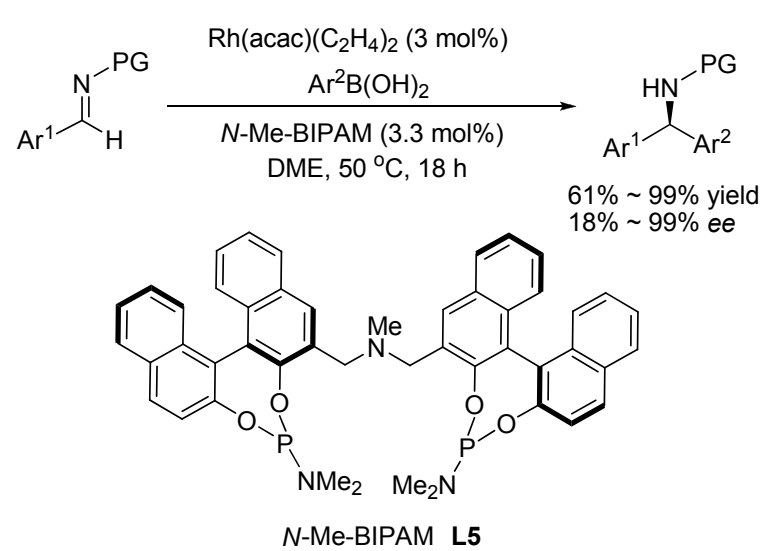

2016 年, Kim 等 ${ }^{[21]}$ 将其发展的双环桥头亚膦酰胺类 配体 L6 成功应用于铑催化的芳基硼酸对芳基醛亚胺的 不对称加成反应中, 取得了 $65 \% \sim 98 \%$ 收率以及 $87 \%$ $96 \%$ ee (Eq. 16). 从底物适应性来看, 亚胺原料芳环上 的取代基电性及位阻效应对反应影响不大; 但当用带有 吸电子及大位阻取代基的芳基硼酸时反应不能发生, 没 有得到加成产物.

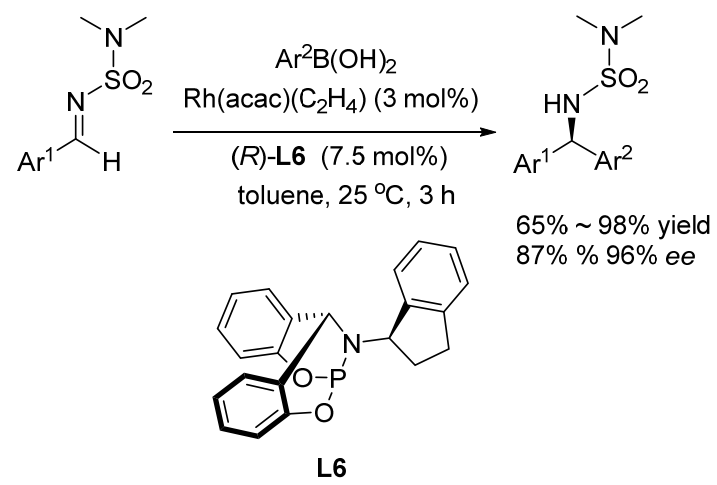

\section{2 .3 手性双烯配体}

\subsubsection{1 不对称芳基化反应}

2004 年, Hayashi 小组 ${ }^{[22]}$ 首次将手性双烯作为配体 用于铑催化的芳基硼酧对 $N$-Ts 保护的苯甲醛亚胺的不 对称加成反应中, 利用 $C_{2}$ 对称双环[2.2.2]-辛二烯 $\mathbf{L 7}$, 反应可以取得非常出色的结果(最高 $98 \%$ 收率，99\% $e e)$, 而且底物适应性也很好, 亚胺以及硼酩芳环上取代 基的空间和电子效应对反应的产率及选择性都没有明 显影响(Eq. 17). 与其它类型的配体相比, 手性双烯在这 类反应中表现出更加优秀的催化活性和对映选择性. 由 于氮上 Ts 保护基通常难以脱除，他们又发展了另外一 类双环[3.3.1]-壬二烯骨架的手性双烯配体 $\mathbf{L 8}$, 实现了 对 $\mathrm{N}$-Ns ( $\mathrm{Ns}=4$-硝基苯磺酰基)亚胺的不对称芳基化, 取得了最高 96\%收率, $99 \% e e^{[23]}$ (Eq. 18).

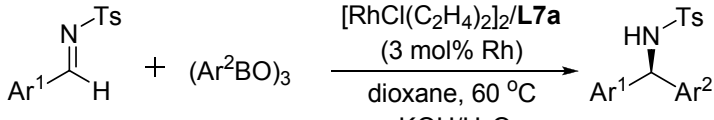

$$
\begin{aligned}
& \mathrm{KOH} / \mathrm{H}_{2} \mathrm{O} \quad 94 \% \sim 99 \% \text { yield } \\
& \text { Ph } \\
& (R, R) \text {-Ph-bod }{ }^{*} \\
& \text { L7a }
\end{aligned}
$$

Selected examples:<smiles>[NH3+]C(c1ccccc1)c1ccc(Cl)cc1</smiles>

$98 \%, 94 \%$ ee<smiles>[Al-]N[C@@H](c1ccccc1)c1ccco1</smiles>

$99 \%, 99 \%$ ee<smiles>COc1ccccc1C([NH3+])c1ccccc1</smiles>

$98 \%, 99 \%$ ee<smiles>Clc1ccc([C@H](N[AsH3])c2ccccc2)cc1</smiles>

$99 \%, 99 \%$ ee<smiles>SC([AsH3])N[C@H](c1ccccc1)c1cccc2ccccc12</smiles>

$95 \%, 98 \%$ ee<smiles>COc1ccc(C(NC(F)(F)F)c2ccccc2)cc1</smiles>

$97 \%, 96 \%$ ee<smiles>Cc1ccccc1[C@H](NC(=S)[S-])c1ccccc1</smiles>

$96 \%, 99 \%$ ee<smiles>COc1ccc(C(NC(F)(F)F)c2ccc(Cl)cc2)cc1</smiles>

$98 \%, 99 \%$ ee

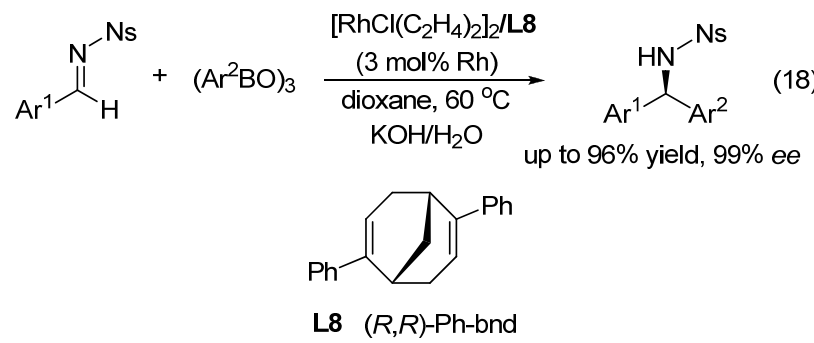


对于反应产物的立体化学, 如 Eq. 19 所示, 推测转 金属化后得到的芳基铑物种与亚胺底物可能有两种配 位方式, 由于过渡态 TS-1 中亚胺氮上的磺酰基与配体 双键上的苯基有较大的空间位阻, 所以 TS-2 为优势过 渡态，芳基迁移后得到主要为 $S$ 构型的产物 ${ }^{[22]}$.

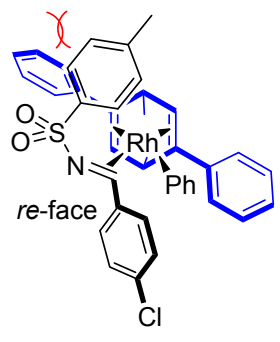

TS-1 (disfavored)

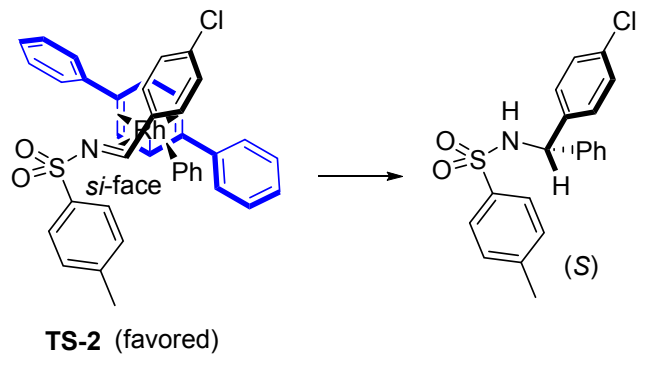

基于双环[2.2.2]-己二烯骨架, Hayashi 小组 ${ }^{[24]}$ 之后 又成功发展了一类 $C_{1}$ 对称的手性双烯配体 L9a. 该配体 在芳基嗍䣶对芳基醛亚胺的不对称加成反应中同样显 示出了非常好的催化活性, 催化剂用量甚至可以低至 $0.3 \mathrm{~mol} \%$, 反应收率和对映选择性均极其优异 $(90 \%$ 98\%收率, 97\% 99.5\% ee) (Eq. 20). 该配体具有高催化 活性的原因可能在于引入吸电子的酯基后, 双键更加缺 电子, 有利于转金属化, 由于转金属化是反应的决速步, 所以该配体表现出更好的催化活性.

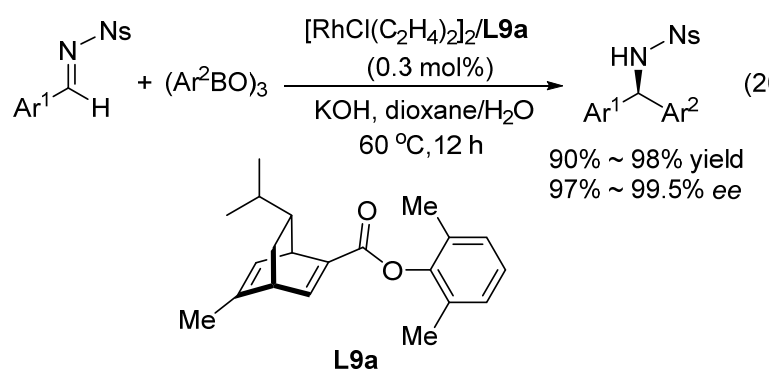

利用双烯配体 L9b, 在相同的反应体系下, Woodward 等 ${ }^{[25]}$ 实现了磺酰二亚胺底物的双不对称芳基化, 以较高的立体选择性得到相应的手性磺酰二胺化合物. 这些产物在吡啶/水体系回流条件下可以脱去二氧化硫 得到手性二芳基甲胺, 但反应有不同程度的消旋化发生 (Eq. 21).

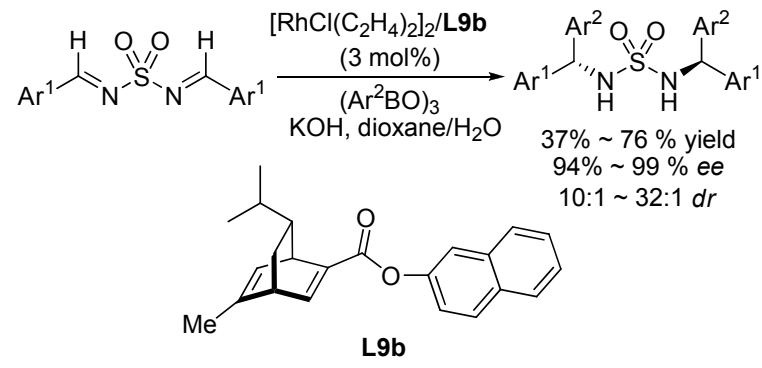

为避免上述保护基脱除过程中产物的部分消旋化， 该小组 ${ }^{[26]}$ 又设计了在亚胺氮上引入另外一种能在温和 条件下方便地脱除的 $N$-叔丁基磺酰胺基(Eq. 22). 但在 配体 L9b 促进的芳基化反应条件下, 部分底物由于亚胺 水解导致收率大大降低, 有意思的是, 当换用 $C_{2}$ 对称的 手性双烯 L7a 为配体时, 反应可以取得较高的收率.

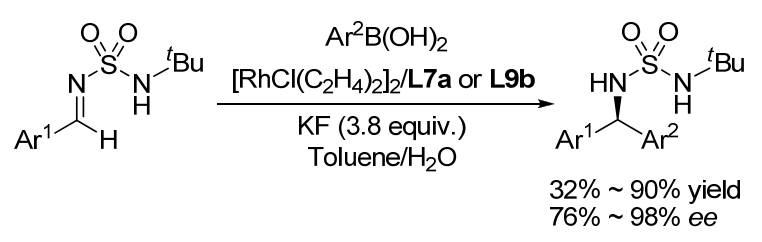

基于 $C_{1}$ 对称的手性双烯配体 $\mathbf{L 9 b}$ 表现出来的高催 化活性, Morimoto 等 ${ }^{[27]}$ 设计了一个串联的不对称芳基化 一氨羰基化环合反应用于手性异吲哚啉类化合物的合 成. 该方法避免了一氧化碳气体的使用，利用芳基醛或 者多聚甲酫为羰基源, 反应中间体无需分离, 底物适应 性好, 产物的收率和光学纯度均不错(Eq. 23).

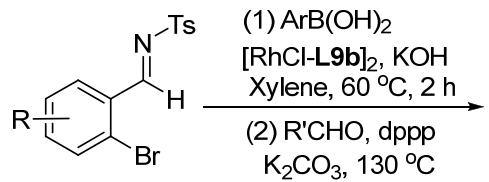

2007 年, $\mathrm{Lin}$ 和 Xu 等 ${ }^{[28]}$ 报道了一类结构简单的基于 双环 [3.3.0]结构的全新手性双烯配体 L10, 分子中两个 顺并的环戊烯环在空间上呈楔形，在催化过程中，两个 烯烃双键与金属铑配位可以提供一个对反应的选择性 控制非常有利的手性环境，尤其在铑催化的芳香酫亚胺 的不对称芳基加成中能取得极其优秀的对映选择性，几 乎所有产物的光学纯度都在 $98 \% \sim 99 \% e e$ (Eq. 24).

带邻位酯基的苯甲醛亚胺同样能很高效地发生反 应，在相同的反应条件下经不对称芳基加成后原位内酰 氨化, 可以直接合成高光学纯度的手性异吲哚啉化合物 (Eq. 25), 而这类化合物中 3-位手性的构建用其它催化 方法通常是比较困难的. 


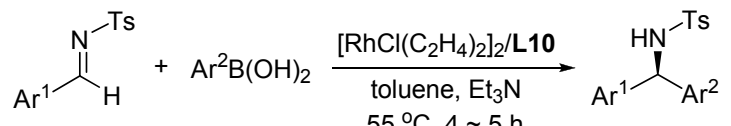

$$
\begin{aligned}
& 55^{\circ} \mathrm{C}, 4 \sim 5 \mathrm{~h} \quad 65 \% \sim 97 \% \text { yield } \\
& \text { 98\% 99\% ee }
\end{aligned}
$$

Selected examples:<smiles>COc1ccc(C(N[Na])c2ccccc2Cl)cc1</smiles>

$65 \%, 99 \%$ ee

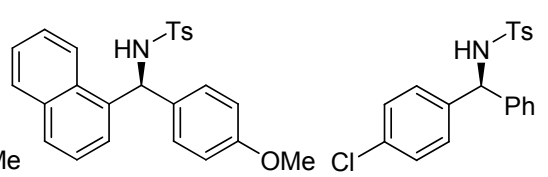

$81 \%, 99 \%$ ee<smiles>[NH3+]C(c1ccccc1)c1ccco1</smiles>

$74 \%, 99 \%$ ee<smiles>COc1ccc(C(N[TeH])c2ccc(Cl)cc2)cc1</smiles>

$97 \%, 99 \%$ ee<smiles>[AsH3-]NC(c1ccc2ccccc2c1)c1cccc2ccccc12</smiles>

$91 \%, 99 \%$ ee<smiles>[3H]/N=C/c1ccccc1C(C)=O</smiles><smiles>O=C1c2ccccc2C(Br)[NH+]1[S-]</smiles>

(25)

进一步的研究发现, 利用嗍酸 $/ \mathrm{KHF}_{2} / \mathrm{H}_{2} \mathrm{O}$ 的组合反 应体系 ${ }^{[29]}$, 在手性双环[3.3.0]-辛二烯配体 L10 促进下, 可以实现对 $N-\mathrm{Ns}$ 亚胺的高对映选择性芳基加成, 以最 高 $96 \%$ 收率和 $99 \% \mathrm{ee}$ 得到相应的二芳基甲胺产物 ${ }^{[30]}$ (Eq. 26).

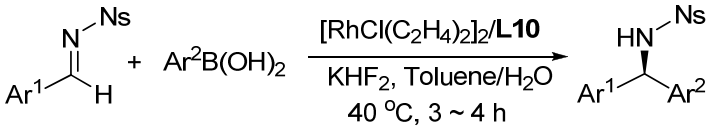

$$
\begin{aligned}
& \text { up to } 96 \% \text { yield, } 99 \% \text { ee }
\end{aligned}
$$

随后，该催化体系又被成功用于芳基硼酸对吲哚醛 亚胺的不对称加成反应中, 产物的光学纯度最高可以达 到 $99 \% e e^{[31]}$ (Eqs. 27, 28). 值得一提的是, 反应能很好 地适用于各种缺电性底物, 为合成传统的 Friedel-Crafts 策略难以实现的 $\alpha$-芳基 3-吲哚甲胺类化合物提供了一 个新的方法. 同时, 对于更加挑战的 2-吲哚醛亚胺, 该 反应体系也能高效地获得目标芳基化产物(72\%收率， $98.5 \% e e)$.

2010 年, Lin, Feng 等 ${ }^{[32]}$ 报道了另外一类 $C_{1}$ 对称的 同时具有桥环和并环结构的手性双烯配体, 发现这类配 体也能高效催化芳基嗍酸对醛亚胺的不对称加成, 反应 几乎都能取得定量的收率, 但立体选择性较之前 $C_{2}$ 对 称的手性双烯配体均有明显的下降(Eq. 29).

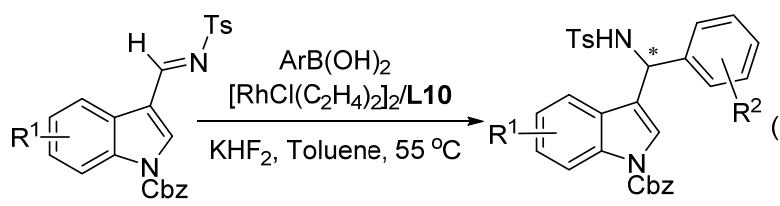
up to $95 \%$ yield, $99 \%$ ee

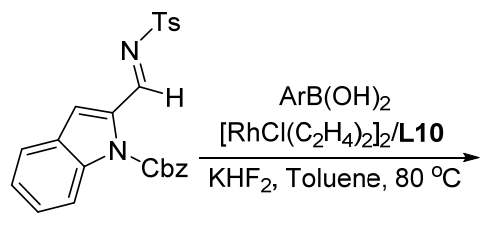<smiles>COc1ccc(C(=N[AlH2])c2cc3ccccc3n2C(=O)OCc2ccccc2)cc1</smiles>

$72 \%, 98.5 \%$ ee

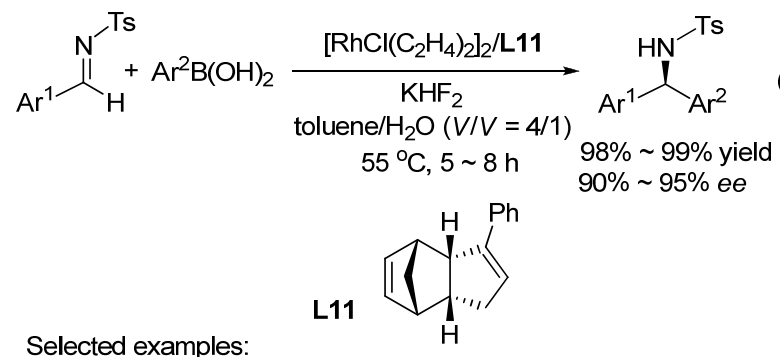

Selected examples:<smiles>COc1ccc(C(N[Al-])c2ccc(C(F)(F)F)cc2)cc1</smiles>

$99 \%, 94 \%$ ee<smiles>Cc1ccc(C(N[AsH3])c2ccccc2)cc1</smiles>

$99 \%, 93 \%$ ee

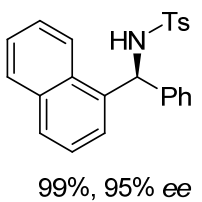<smiles>COc1ccc(C(N[I-])c2cccc3ccccc23)cc1</smiles>

$98 \%, 90 \%$ ee<smiles>[AlH2]NC(c1ccccc1)c1ccc(Cl)cc1</smiles>

$98 \%, 94 \%$ ee
脂肪亚胺的不对称芳基加成报道很少，一般来说， 需要找到一个活性很高的催化剂能促使芳基化反应顺 利发生，同时反应体系中要避免使用酸或碱以减少副反 应的发生. 2011 年, Lin 小组 ${ }^{[33]}$ 发现利用铑/烯烃配合物 $[\mathrm{Rh}(\mathbf{L 1 0})(\mathrm{OH})]_{2}$ 可以同时满足如上两个条件，体系中分 子篮的加入也能进一步提高收率. 反应的底物适应性较 好，并且收率和对映选择性都很出色 $(87 \%$ ～99\% 收率， 91\% 99\% ee). 结合反应后分子内取代环化策略，该方 法可以用于手性 2-芳基吡咯烷及 2-芳基哌啶类化合物 的高效不对称合成(Eqs. 30, 31). 此外, 该催化体系同样 适用于 $N-N s$ 亚胺，反应都可以取得良好的收率 $(87 \%$ 


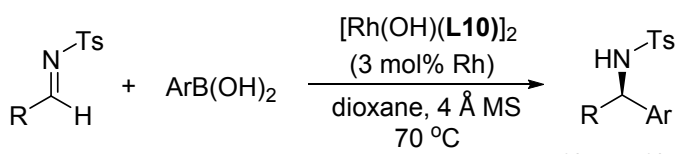

$$
\begin{aligned}
& \text { 87\% 99\% yield }
\end{aligned}
$$$$
\text { Selected examples: }
$$<smiles>[3H]NC(CC)c1ccccc1</smiles>

$99 \%,>99 \%$ ee<smiles>CC(C)C(N[TeH])c1ccccc1</smiles>

$94 \%,>99 \%$ ee<smiles>CCC(N[AlH2])c1ccc(C(F)(F)F)cc1</smiles>

$93 \%, 99 \%$ ee<smiles>[Al-]NC(c1ccccc1)C1CCCCC1</smiles>

$93 \%,>99 \%$ ee<smiles>CCC(N[As])c1cccc(OC)c1</smiles>

$98 \%, 99 \%$ ee<smiles>CCC(CC)C(N[TeH])c1ccccc1</smiles>

$95 \%,>99 \%$ ee<smiles>[Al-]N[C@@H](CCCOCc1ccccc1)c1ccccc1</smiles>

$90 \%,>99 \%$ ee<smiles>[AlH2]C(CCCCCl)c1ccccc1</smiles>

$90 \%,>99 \%$ ee

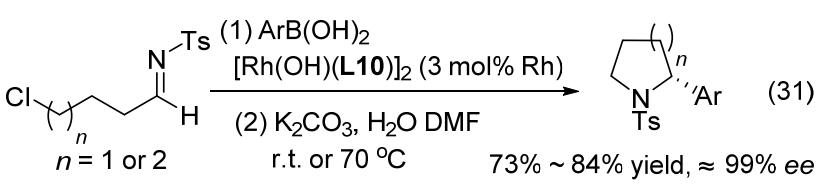

99\%)和极其优秀的对映选择性( $>99 \% e e)$.

2010 年, $\mathrm{Du}$ 小组 ${ }^{[34]}$ 报道了一类基于手性联菜骨架 的开链的手性双烯配体在铑催化的芳基醛亚胺的不对 称芳基加成反应中的应用. 研究发现, 配体分子中联菜 骨架上 3,3'位的取代对催化剂的活性和立体选择性有明 显的影响, 当 3,3'位无取代时, 该类双烯配体几乎不能 催化反应. 从反应的底物适应性来看, 该催化体系似乎 仅适用于给电性很强的对位烷氧基取代的苯硼酸; 当选 用对甲基苯硼酸时，收率下降至 48\% (Eq. 32).

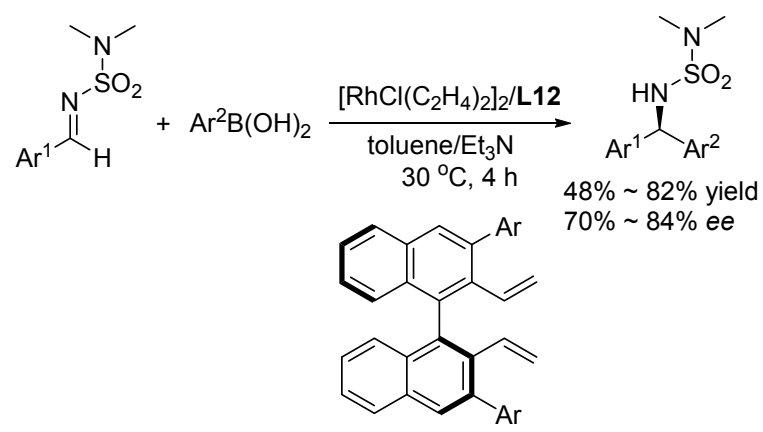

$\mathrm{Ar}=4-\mathrm{MeOC}_{6} \mathrm{H}_{4} \mathrm{~L} \mathbf{2 1 2}$

2014 年, $\mathrm{Wu}$ 小组 ${ }^{[35]}$ 报道了另一类 $C_{1}$ 对称手性双烯 配体 L13a 促进的铑催化的芳基嗍酸对芳香醛亚胺的不 对称加成反应，该反应同时适用于 $N-\mathrm{Ts}$ 及 $N-\mathrm{Ns}$ 亚胺并 且底物适应性较好; 催化剂具有较高的反应活性, 反应 $1 \mathrm{~h}$ 便可完全, 可以以 56\% 99\%收率, 90\% 99\% ee 得
到手性二芳基甲胺产物. 在亚胺底物中引入合适的官能 才, 其加成产物经过几步简单转化可用于手性四氢异喹 啉类化合物的合成(Eq. 33, Scheme 3).
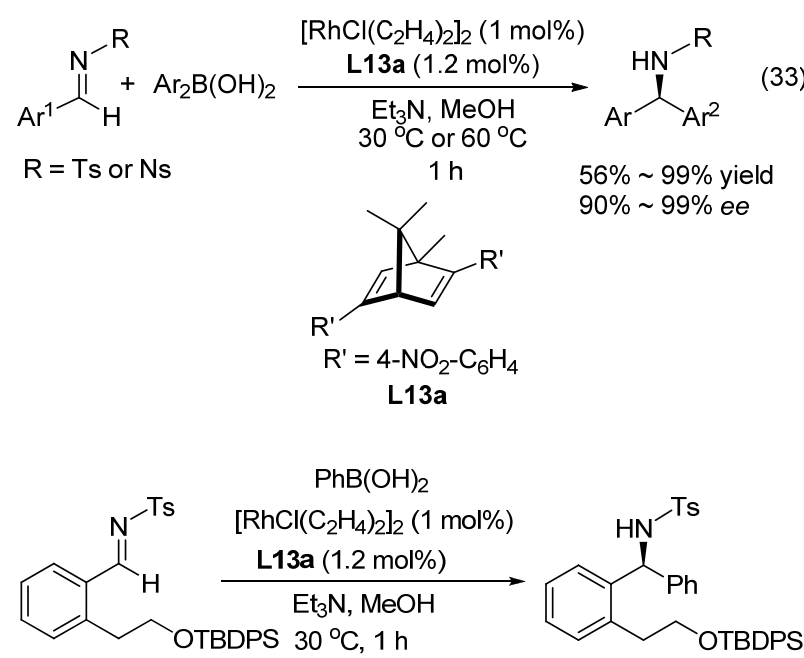

$96 \%, 95 \%$ ee

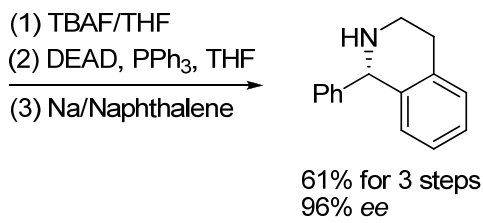

图式 3 手性四氢异喹啉类化合物的合成

Scheme 3 Synthesis of tetrahydroisoquinoline

\subsubsection{2 不对称烯基化及烯丙基化反应}

手性双烯配体不仅适用于醛亚胺的不对称芳基化 反应，同时还能用于高效的不对称烯基化以及烯丙基化 反应. 2012 年, Lam 小组 ${ }^{[36]}$ 报道了铑催化下手性双烯配 体促进的烯基氟硼酸钾对醛亚胺的不对称加成反应(Eq. 34). 在最初的研究中, 以苯甲醛亚胺为底物, 虽然反应 可以顺利发生，但产物的 $e e$ 值都不理想，最好仅在 $55 \%$. 考虑到在烯基化反应过程中亚胺 $\mathrm{C}=\mathrm{N}$ 双键 $Z / E$ 构型变化的可能影响, 作者尝试了以 $\mathrm{C}=\mathrm{N}$ 双键构型固 定的环状磺酰醛亚胺为反应底物进行不对称烯基化(Eq. 35). 果然，反应结果有了明显的提高，不同的烯基氟硼 酸钾都能实现对各种环状醛亚胺的不对称加成, 并且给 出中等到优秀的收率(50\% 94\%)以及出色的对映选择

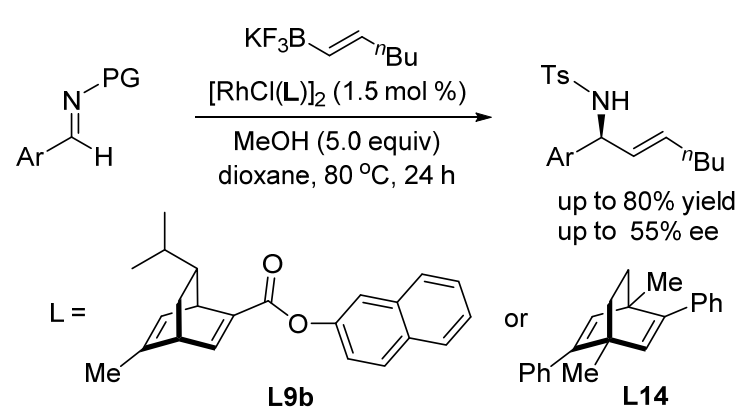


<smiles>[R]C=C([R])[As]</smiles>

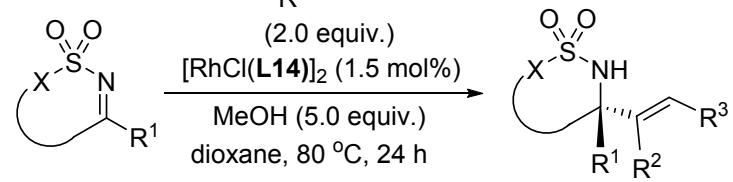

up to $94 \%$ yield, up to $99 \%$ ee

Selected examples:<smiles>O=S1(=O)N[C@@H](/C=C/C2CCCCC2)c2ccccc2O1</smiles>

$94 \%, 99 \%$ ee<smiles>C/C=C/[C@H]1NS(=O)(=O)Oc2cc(Br)ccc21</smiles>

$92 \%, 98 \%$ ee<smiles>CC=C(C)[C@H]1NS(=O)(=O)Oc2ccccc21</smiles>

$94 \%, 94 \%$ ee<smiles>CCCC=CC1NS(=O)(=O)c2ccccc21</smiles>

$68 \%, 90 \%$ ee

性(94\% 99\% ee). 值得一提的是, 在相同的反应体系 下, 五元环状磺酰酮亚胺的不对称烯基化反应也能取得 68\%收率和 $90 \%$ ee.

上述催化体系也可以进一步用于不对称烯丙基化 反应 ${ }^{[37]}$. 利用烯丙基氟硼酸钾或者取代的烯丙基氟喼 酸钾对环状磺酰醛亚胺及酮亚胺进行不对称加成, 反应

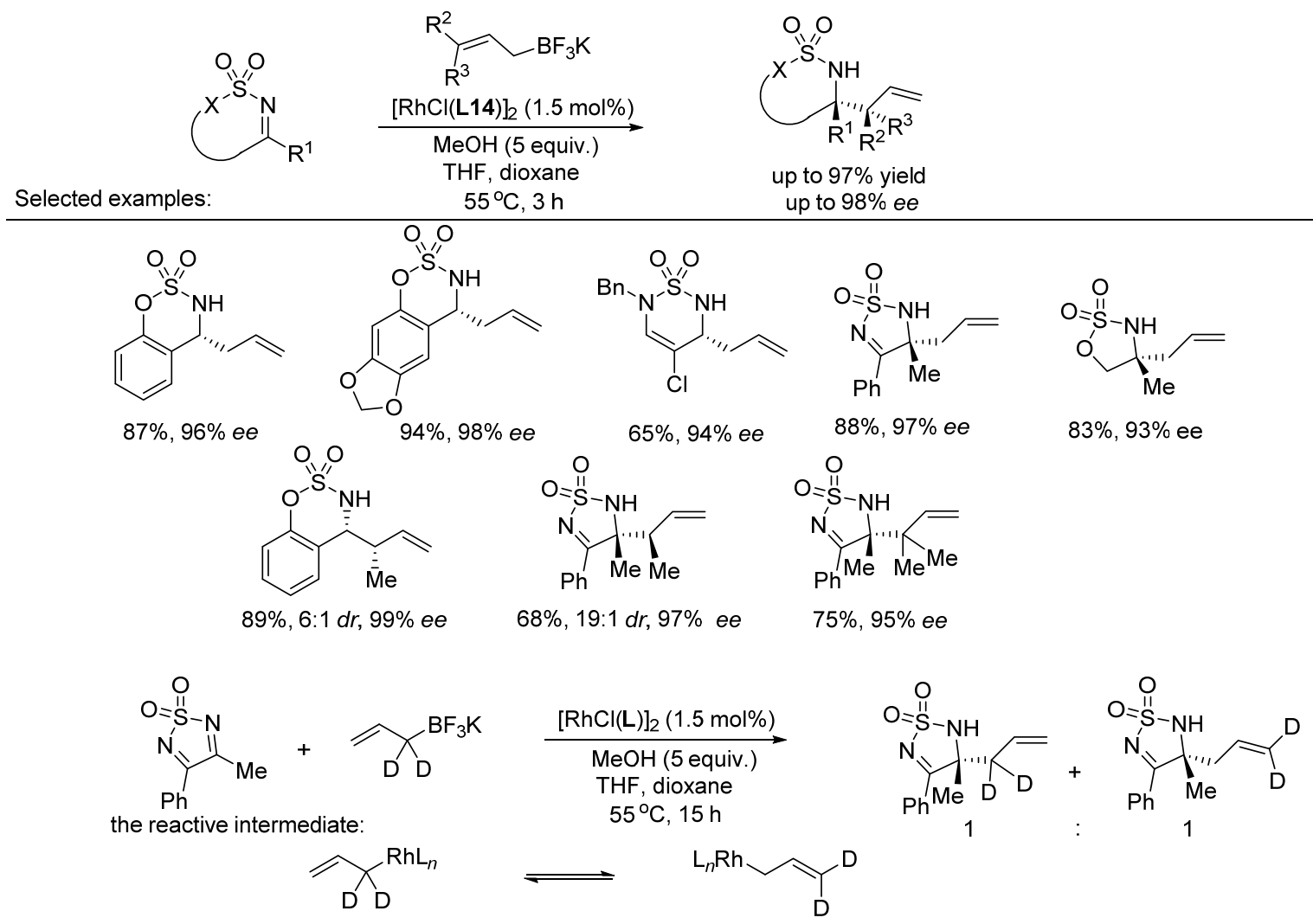

图式 4 氛代实验

Scheme 4 Deuterium labeling experiment 


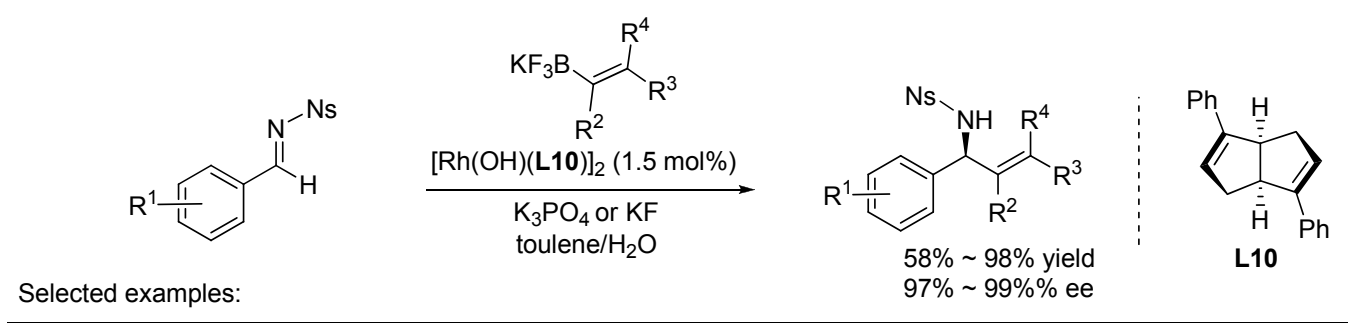

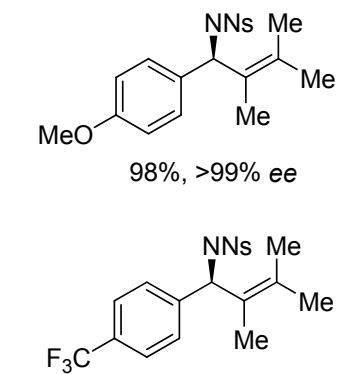

$92 \%,>99 \%$ ee<smiles>COc1ccc(C(C2=CCCCC2)[N+]([N])([N-])[O-])cc1</smiles>

$99 \%,>99 \%$ ee<smiles>COc1ccc(C(/C=C/c2ccccc2)[N+]#N)cc1</smiles>

$71 \%, 98 \%$ ee<smiles>CC(C)=C(C)C(c1ccccc1Br)[N+]([NH3+])=O</smiles>

$58 \%,>99 \%$ ee<smiles>COc1ccc(C(C=Cc2ccc(Cl)cc2)[N+](c2ccccc2)[N+](=O)[O-])cc1</smiles>

$93 \%,>99 \%$ ee<smiles></smiles>

$91 \%, 99 \%$ ee<smiles>COc1ccc(/C=C/C(c2cccs2)[N+](=O)[O-])cc1</smiles>

$90 \%,>99 \%$ ee

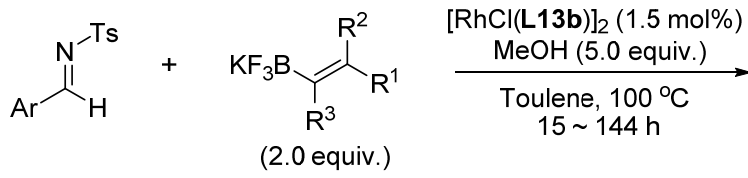<smiles>[R]C([R])=C([R])N[Te]</smiles>

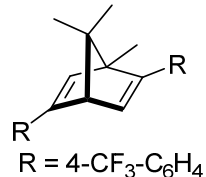

$73 \% \sim 97 \%$ yield $72 \sim>99.5 \%$ ee

(L13b)

$\mathrm{KF}_{3} \mathrm{~B} \leadsto \mathrm{OH}$

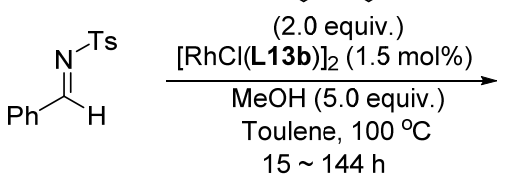<smiles>OC/C=C/[C@H](N[Te])c1ccccc1</smiles>

$88 \%, 94 \%$ ee
(1) $\mathrm{H}_{2}, \mathrm{Pd} / \mathrm{C}, \mathrm{MeOH} / \mathrm{EA}$

(2) DEAD, $\mathrm{PPh}_{3}, \mathrm{THF}$<smiles>CN1CCC[C@H]1c1ccccc1</smiles>

$45 \%$ for two steps $92 \%$ ee

图式 5 手性烯丙基胺的合成与衍生

Scheme 5 Synthesis and derivation of chiral allylic amines

\section{2 .4 杂原子一烯烃配体}

2011 年, Shintani、Hayashi 等 ${ }^{[40]}$ 设计了一类五元环 状膦烯配体, 在铑催化的芳基硼酸对苯甲醛亚胺的不对 称加成反应中, 取得了不错的结果, 尤其是反应的底物 适应性很好，不仅适用于芳基和杂芳基的亚胺底物，脂 肪亚胺也能取得较好的结果(Eq. 38).

2013 年, $\mathrm{Xu}$ 小组 ${ }^{[41]}$ 以简单手性硫烯为配体, 成功实 现了铑催化下芳基硼酸对六元环状磺酰醛亚胺的不对 称加成反应. 在室温条件下, 反应即可高效高选择性地 进行, 以优秀的收率(93\% 99\%)得到一系列近乎光学 纯的芳基化产物( $97 \%$ \% 9 \% ee). 对反应过渡态的分析 认为与双键相连的 $\mathrm{R}$ 基团的空间位阻作用使得环状醛 亚胺的环完全倾向于处在远离 $\mathrm{R}$ 的位置( $\mathrm{B}$ 中所示), 这 样, 芳基从亚胺 $r e$-面迁移, 从而得到 $(R)$ 构型的产物(Eq. 39, 图 3).

最近, $\mathrm{Xu}$ 等 ${ }^{[42]}$ 又成功实现了铑催化下硫烯配体 $\mathbf{L 1 7}$
$\left(\mathrm{R}^{\prime} \mathrm{BO}\right)_{3}$<smiles>[R]C=[13N][Na]</smiles>
$\underset{\mathrm{KOH}(0.2 \text { equiv. })}{\stackrel{\mathrm{RhCl}(\mathrm{L} 15)]_{2}(5 \mathrm{~mol} \% \mathrm{Rh})}{\text { dioxane } / \mathrm{H}_{2} \mathrm{O}(\mathrm{V} / \mathrm{V}=50 / 1)}} \underset{\begin{array}{c}71 \% \sim 93 \% \text { yield } \\ 60^{\circ} \mathrm{C}, 6 \mathrm{~h}\end{array}}{\begin{array}{c}89 \% \sim 97 \% \text { ee } \\ \mathrm{Ph}_{2} \mathrm{P}-\mathrm{R}^{\prime}\end{array}}$

Bกั

L15

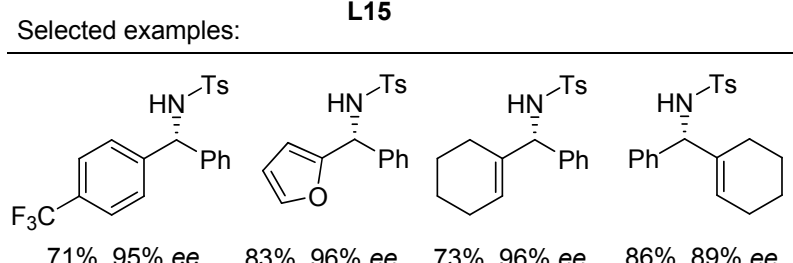

促进的芳基硼酐对 $N, N$-二甲基氨磺酰亚胺的不对称加 成反应(Eq. 40). 这个反应的底物适应性非常好, 克服了 之前利用 MonoPhos 类单膦配体 $\mathbf{L 3}^{[18]}$ 、双环桥头亚膦 


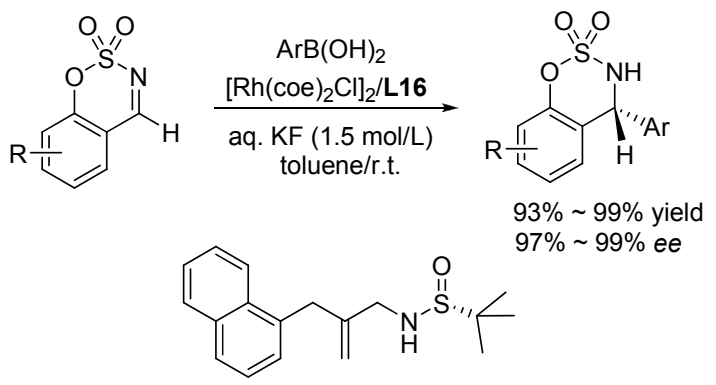

L16

Selected examples:

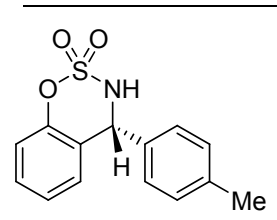

$96 \%, 99 \%$ ee<smiles>COc1ccc([C@H]2NS(=O)(=O)Oc3ccc(OC)cc32)cc1</smiles>

$98 \%, 97 \%$ ee<smiles>COc1ccc([C@H]2NS(=O)(=O)Oc3c(OC)cccc32)cc1</smiles>

$96 \%, 97 \%$ ee

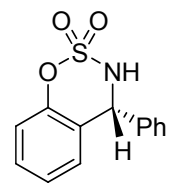

$98 \%, 99 \%$ ee<smiles>O=S1(=O)N[C@H](c2ccccc2)c2cc(Cl)ccc2O1</smiles>

$93 \%, 99 \%$ ee

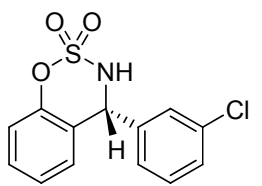

$98 \%, 99 \%$ ee<smiles>COc1ccc2c(c1)OS(=O)(=O)N[C@H]2c1ccccc1</smiles>

$99 \%, 99 \%$ ee
(39)

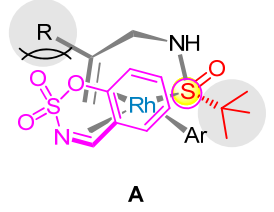

si-face (unfavorable)

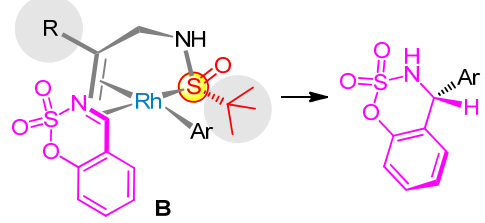

re-face (favorable)

图 3 推测的反应过渡态

Figure 3 Proposed reaction transition state

酰胺类配体 $\mathbf{L 6}{ }^{[21]}$ 以及开链双烯配体 $\mathbf{L 1 2}{ }^{[34]}$ 的底物局限 性，通过合理的组合，可以几乎完美地得到各种二芳基 甲胺产物，反应还尤其适用于芳基邻位有取代基的底 物，可以获得 $97 \% \sim 99 \%$ ee 的极高的对映选择性. 值得 一提的是，该催化体系也适用于 $N$-Ts 亚胺的不对称芳 基加成. 基于该方法，两个邻位有羟乙基取代的亚胺经 加成反应, 得到光学纯度为 $99 \% e e$ 的相应产物, 再经简 单转化成功用于治疗尿频的药物分子 Solifenacin 以及作 为多巴胺受体 D1 探针分子的天然产物 $(S)-(+)$-Cryptostyline II 的高效合成(Eq. 41). 该研究也为构建药物研 究中重要的手性 1-芳基-1,2,3,4-四氢异喹啉骨架提供了 一个简单、有效的催化不对称方法.

\subsection{5 手性嚊唑啉配体}

2012 年, Zeng 小组 ${ }^{[3]}$ 报道了二价钯催化下双恶唑 啉配体促进的芳基硼酸对乙醛酸酯亚胺的不对称加成 反应(Eq. 42). 有趣的是, 与之前 $\mathrm{Lu}$ 小组报道的需要阳

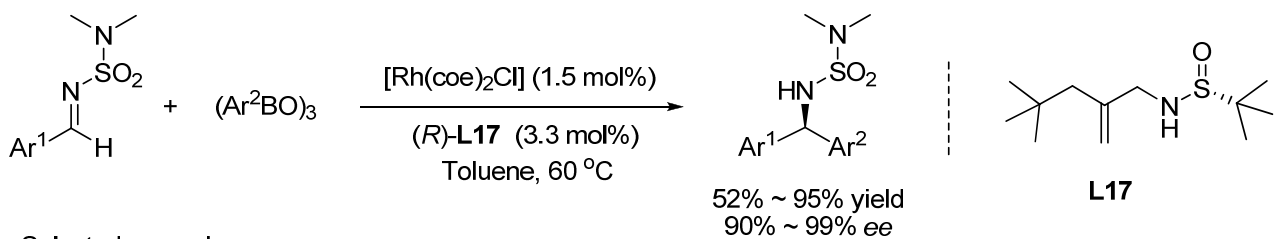

Selected examples:<smiles>CN(C)[N+](=O)N[C@H](c1ccccc1)c1ccc(C(F)(F)F)cc1</smiles>

$91 \%, 99 \%$ ee<smiles></smiles>

$96 \%, 98 \%$ ee<smiles>COc1ccc(C(N[N+](=O)[O-])c2ccc([N+](=O)[O-])cc2)cc1</smiles>

$85 \%, 98 \%$ ee

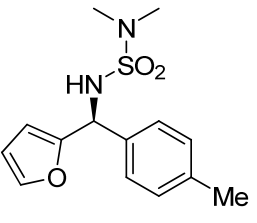

$52 \%, 98 \%$ ee

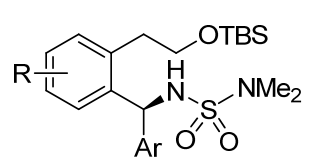

$99 \%$ ee

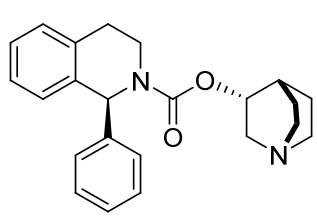

$99 \%$ ee Solifenacin

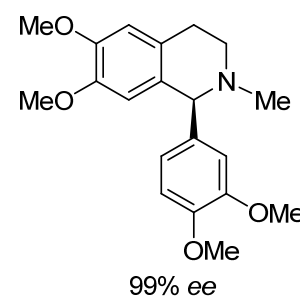

(S)-(+)-Cryptostyline II 


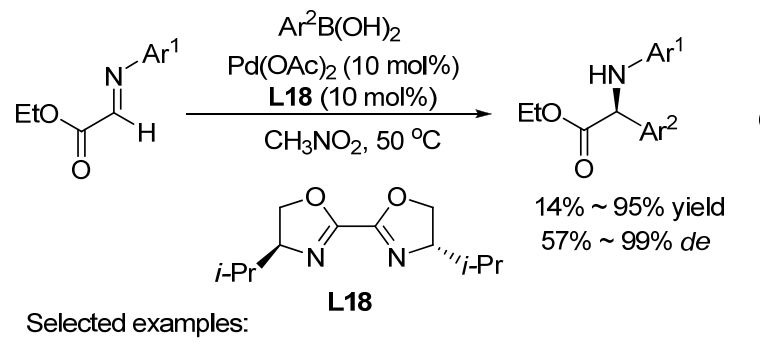<smiles>CCOC(=O)C(Nc1ccc(Cl)cc1)c1ccccc1</smiles>

$93 \%, 97 \%$ ee<smiles>CCOC(=O)C(Nc1ccc(OC)cc1)c1ccccc1OC</smiles>

$48 \%, 84 \%$ ee<smiles>CCOC(=O)C(Nc1ccc(OC)cc1)c1ccc(F)cc1</smiles>

$59 \%, 94 \%$ ee

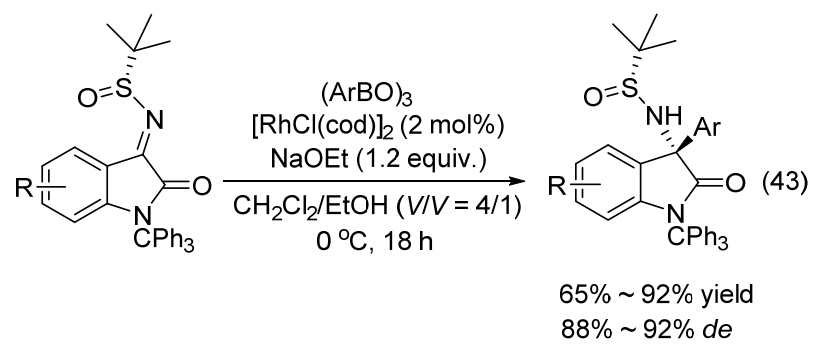<smiles>[R]C(C)=NCc1ccccc1</smiles>

离子型钯催化不同, 反应在 $\mathrm{Pd}(\mathrm{OAc})_{2} /$ 双噁唑啉配体催 化下便可以取得较高的收率, 说明噁唑啉类配体不仅可 以调控该反应的立体选择性, 同时也可以提高催化剂的 反应活性. 在 $10 \mathrm{~mol} \%$ 的催化剂作用下, 该反应对于富 电子硼酸能取得较好的结果, 但对于缺电子硼酸反应收 率有一定的下降.

\section{2 酮亚胺的不对称加成}

酮亚胺经不对称加成反应可以得到含季碳立体中 心的 $\alpha$-手性胺类化合物, 但相比前述醛亚胺, 酮亚胺的 反应性大大降低, 并且由于反应位点两侧空间区分较 小, 所以要实现其立体选择性控制通常更难.

\section{1 手性辅剂策略}

2011 年, Ellman 小组 ${ }^{[44]}$ 报道了铑催化下芳基硼酐对 靛红叔丁亚磺酰亚胺的不对称芳基化反应，以合成含季 碳手性中心的 3-芳基 3-氨基吲哚酮. 反应在一价铑催化 下顺利进行, 靛红母核上的取代及芳基硼酐上的取代基 对反应的影响不大，以 $65 \% \sim 92 \%$ 收率和中等到好的 立体选择性( $88 \% \sim 92 \% d e$ ) 得到目标产物(Eq. 43).

\section{2 手性配体策略}

\subsection{1 手性双膦配体}

2006 年, Shibasaki, Kanai 等 ${ }^{[45]}$ 报道了 $\mathrm{Cu}(\mathrm{I}) / \mathrm{La}(\mathrm{III})$ 共催化的环戊基-DuPhos 促进的烯丙基频那醇嗍酯对酮 亚胺的不对称加成反应，以 $76 \% \sim 98 \%$ 收率, $23 \% \sim 93 \%$ $e e$ 得到了一系列 $\alpha$-芳基-高烯丙氨类化合物(Eq. 44). 异

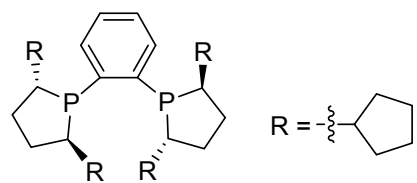

Cyclopentyl-DuPhos

L19

Selected examples:

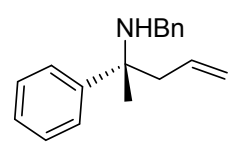

$92 \%, 89 \%$ ee<smiles>C=CC[C@](C)(N)c1ccc2ccccc2c1</smiles>

$88 \%, 92 \%$ ee<smiles>C=CC[C@](C)(N)c1cccc(F)c1</smiles>

$89 \%, 87 \%$ ee<smiles>C=CC[C@](C)(CCc1ccccc1)Nc1ccccc1</smiles>

$98 \%, 23 \%$ ee
丙醇锂作为共催化剂可以显著提高反应的活性及立体 选择性, 核磁研究表明其可以有效增加活性亲核物种 (烯丙基铜试剂)的浓度. 苄基保护基可以经 IBX 氧化成 亚胺中间体，随后在盐酸水溶液中脱除，产物光学活性 保持.

2015 年, Jarvo 等 ${ }^{[46]}$ 报道了银催化下 Walphos 促进的 联烯频那醇硼酯对环状磺酰酮亚胺的不对称加成, 成功 合成了一系列含季碳手性中心 $\alpha$-芳基/烷基-高炔丙氨类 化合物，取得了 $90 \% \sim 98 \%$ ee (Eq. 45).

几乎同时, Kong, McLaughlin 等 ${ }^{[47]}$ 报道了一价铑催 化的 Walphos 促进的芳基及烯基硼酸对环状磺酰酮亚胺 的不对称加成反应，芳基酮亚胺及脂肪酮亚胺均能适用 于此反应，取得了 $40 \% \sim 99 \%$ 收率， $88 \% \sim 99 \%$ ee (Eq. 46). 
<smiles>[R]C1=NS(=O)(=O)c2ccccc21</smiles>

$\mathrm{AgPF}_{6}(10 \mathrm{~mol} \%)$

L20 (12 mol\%)

$\mathrm{KO}$-Bu $(20 \mathrm{~mol} \%)$

$\Longrightarrow$

$\mathrm{HOt}$-Bu (1.1 equiv.)

DMF, r.t., $18 \mathrm{~h}$

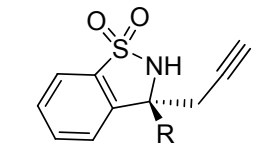

$\mathrm{R}=\mathrm{Aryl}$, heteroaryl, alkyl $69 \% \sim 89 \%$ yield $90 \% \sim 98 \%$ ee

(45)

$\mathrm{F}_{3} \mathrm{C}$<smiles>CC(c1ccccc1-c1ccccc1)P(c1cc(C(F)(F)F)cc(C(F)(F)F)c1)c1cc(C(F)(F)F)cc(C(F)(F)F)c1</smiles>

L20

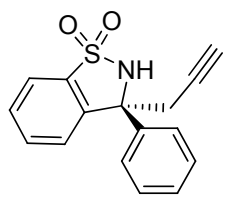

$76 \%, 98 \%$ ee

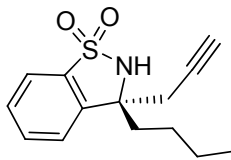

$84 \%, 98 \%$ ee

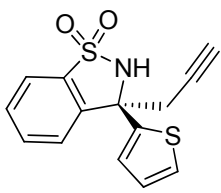

$89 \%, 94 \%$ ee

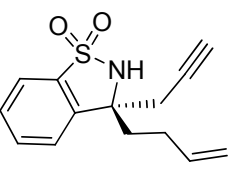

$88 \%, 96 \%$ ee

\subsection{2 手性烯烃类配体}

2010 年, Shintani, Hayashi 等 ${ }^{[48]}$ 首次实现了铑催化 下双环[2.2.2]手性双烯配体促进的四芳基硼钠试剂对酮 亚胺的不对称加成反应，以 $53 \% \sim 97 \%$ 的收率和 94\% 99.5\% ee 得到了一系列含 $\alpha$-季碳手性中心的手性 胺. 由于酮亚胺的反应性较低，所以作者采用了亲核能 力更强的四芳基硼钠试剂，反应中铑/双烯络合物催化 剂需要事先制备，体系具有较好的底物适应性(Eq. 47).

在此基础上，该小组 ${ }^{[49]}$ 随后又发现可以用更加容 易制备的芳基氟硼酸钾试剂代替四芳基硼钠，并且将亚 胺氮上的保护基拓展至易脱除的 Ns，反应同时还适用 于杂芳基硼酸及烯基硼酸, 均能取得良好的收率和优异 的对映选择性(Eq. 48).

2012 年, Nishimura, Hayashi ${ }^{[50]}$ 又成功实现了 $C_{1}$-对 称的手性双烯配体 L9c 促进的五元和六元环状磺酰酮 亚胺的不对称芳基化反应. 同样，相应的铑/烯烃配合物 催化剂需要事先制备，在其催化下，可以以 $70 \%$ ～93\% 的收率和 $93 \%$ ～99\% ee 获得一系列含季碳手性中心的 苯并磺内酰胺和磺胺内酯类化合物. 其中苯并磺胺内酯 产物在四氢铝锂的作用下很容易开环得到 $\alpha$-三芳基取

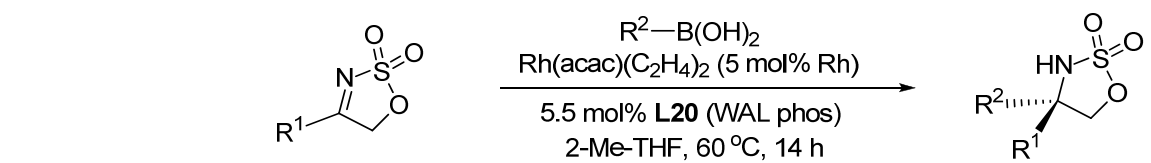

$\mathrm{R}^{1}=$ aryl, $58 \% \sim 99 \%$ yield, $88 \% \sim 99 \%$ ee $\mathrm{R}^{1}=$ alkyl, $40 \% \sim 82 \%$ yield, $93 \% \sim 96 \%$ ee

Selected examples:<smiles>CCC/C=C/[C@]1(c2cc(F)cc(F)c2)COS(=O)(=O)N1</smiles>

$75 \%$, >99\% ee
$84 \%, 88 \%$ ee<smiles>O=S1(=O)N[C@@](c2ccccc2)(c2cccc3ccccc23)OS1(=O)=O</smiles>

$65 \%,>99 \%$ ee<smiles>COc1ccc(C2(NS(=O)(=O)O)OCC23CC3)cc1</smiles>

$82 \%, 94 \%$ ee

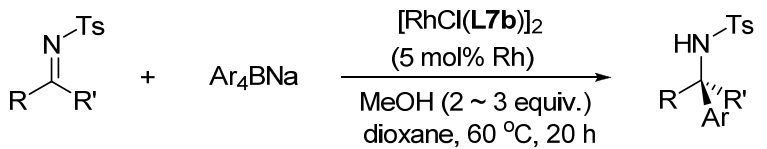

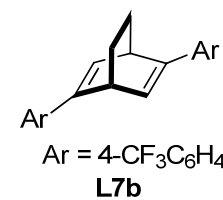

L7b<smiles>[NH3+][C@@H](c1ccccc1)c1ccc(Cl)cc1</smiles>

$83 \%, 97 \%$ ee<smiles>C[C@@](NC(F)([AsH3])c1ccccc1)(c1ccccc1)c1ccc2ccccc2c1</smiles>

$82 \%, 94 \%$ ee

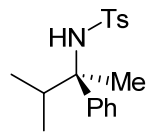

$64 \%, 98 \%$ ee<smiles>[N-]=C1c2ccccc2CC[C@@]1(N)c1ccccc1</smiles>

$97 \%, 99.5 \%$ ee

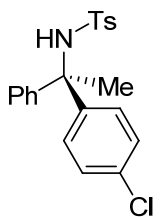

$86 \%, 98 \%$ ee

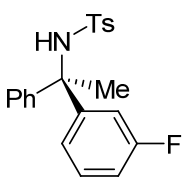

$63 \%, 95 \%$ ee 


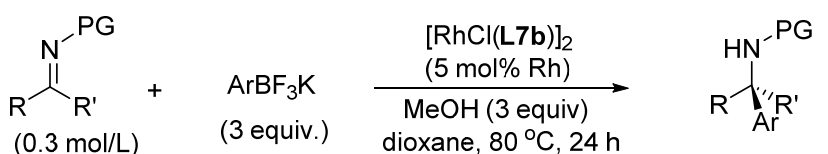

代的手性甲胺, 这类化合物由于三个芳基取代基非常相 似, 要实现它们的高效不对称合成通常是非常困难的 (Eq. 49).

2013 年, $\mathrm{Xu}$ 小组 ${ }^{[51]}$ 发展了新的支链结构的手性亚 磺酰胺一烯烃配体, 成功用于铑催化的硼酸对环状酮亚 胺的不对称芳基化反应中, 首次实现了含季碳手性的相 应羧基和三氟甲基取代的系列磺内酰胺和磺胺内酯类 化合物的高对映选择性合成. 利用简单硫烯配体 L16, 反应在温和的条件下就可以进行, 产物的对映选择性最 高为 $99 \%$ ee (Eq. 50). 这里手性硫烯配体相比之前报道 的双烯及双膦配体, 结构更加简单, 合成极其方便, 而 且反应中无需预先制备好铑配合物.

1,2,5-噻二唑啉-1,1-二氧化物结构广泛存在于生物
活性天然产物和药物分子中, 但手性噻二唑啉的合成报 道很少. 在进一步的研究中, $\mathrm{Xu}$ 等 ${ }^{[52]}$ 利用相同的原位生 成的手性铑/硫烯配合物为催化剂, 通过环状磺酰二酮 亚胺的不对芳基化反应，成功实现了一系列含四取代手 性中心的 2,3-二氢-1,2,5-噻二唑啉-1,1-二氧化物的高对 映选择性合成. 反应在非常温和的条件下进行，收率及 $e e$ 值均高达 99\% (Eq. 51). 产物经一步开环反应可以方 便地用于其它方法难以实现的手性 $\alpha$-叔氨酮的构建, 为 这类重要化合物的合成提供了新的对映选择性方法.

相比芳香酮亚胺，烷基取代的脂肪酮亚胺的不对称 加成更加挑战. 通过对反应条件的优化, $\mathrm{Xu}$ 小组 ${ }^{[53]}$ 又利 用手性硫烯配体 L16 成功实现了铑催化下五元和六元 环状 $N$-磺酰脂肪酮亚胺的不对称芳基化反应，成功合

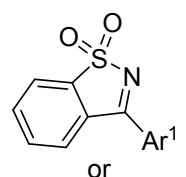

or<smiles>O=S1(=O)N=C(c2ccccc2)c2ccccc2O1</smiles>

Selected examples:
$\left(\mathrm{Ar}^{2} \mathrm{BO}\right)_{3}$

$\left[\mathrm{RhCl}(\mathbf{L} \text { 9c) }]_{2}\right.$ (5 mol\% Rh) $\mathrm{K}_{3} \mathrm{PO}_{4}$ (1 equiv.)

t-amyl alcohol, dioxane

$60{ }^{\circ} \mathrm{C}, 12 \mathrm{~h}$

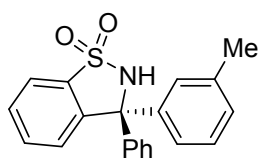

$99 \%, 97 \%$ ee<smiles>COc1ccc([C@@]2([O-])NS(=O)(=O)c3ccccc32)cc1</smiles>

$92 \%, 98 \%$ ee

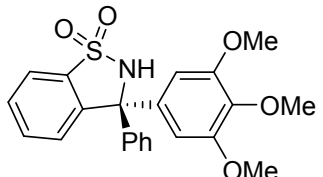

$98 \%, 95 \%$ ee

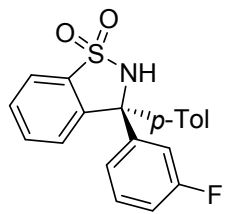

$97 \%, 97 \%$ ee

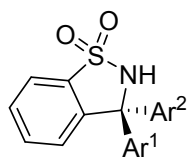

or

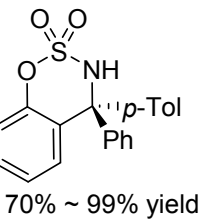

$93 \% \sim 99 \%$ ee

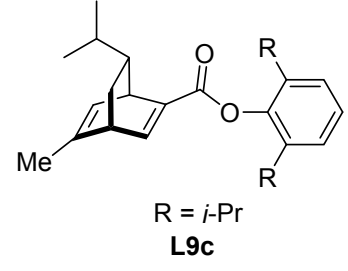

(49)

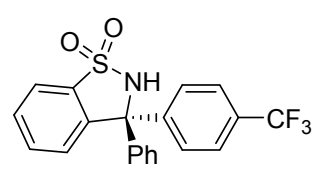

$70 \%, 94 \%$ ee

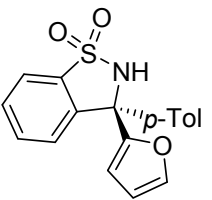

97\%, 99\% ee

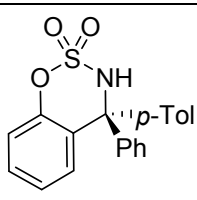

$71 \%, 99 \%$ ee

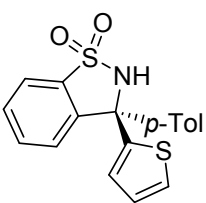

$99 \%, 93 \%$ ee 
<smiles>[R1]C1=NS(=O)(=O)c2ccccc21</smiles><smiles>[R]C1=NS(=O)(=O)Oc2ccccc21</smiles>

$\left[\mathrm{Rh}(\mathrm{COe})_{2} \mathrm{Cl}\right]_{2} / \mathrm{L} \mathbf{L}$

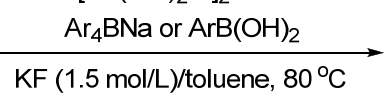

or

Dioxane, $\mathrm{CH}_{3} \mathrm{OH}, 80^{\circ} \mathrm{C}$<smiles>[R17]C1NS(=O)(=O)c2ccccc21</smiles>

$\mathrm{R}^{1}=$ Aryl, COOEt<smiles>[R]C1([Te])NS(=O)(=O)Oc2ccccc21</smiles><smiles>C=C(CNS(=O)C(C)(C)C)Cc1cccc2ccccc12</smiles>

L16

$26 \% \sim 99 \%$ yield, $85 \% \sim 99 \%$ ee<smiles>CCOC[C@]1(c2cccc3ccccc23)NS(=O)(=O)c2ccccc21</smiles>

$90 \%, 99 \%$ ee<smiles>Cc1ccc(C2(c3ccc(Cl)cc3)NS(=O)(=O)c3ccccc32)cc1</smiles>

$85 \%, 97 \%$ ee<smiles>CCOC(=O)[C@]1(c2ccccc2OC)NS(=O)(=O)c2ccccc21</smiles>

$35 \%, 95 \%$ ee<smiles>COc1ccc(C2(c3cccc(C)c3)NS(=O)(=O)c3ccccc32)cc1</smiles>

$88 \%, 98 \%$ ee<smiles>CCOC(=O)C1(c2cccc(C)c2)NS(=O)(=O)c2ccc(F)cc21</smiles>

$76 \%, 90 \%$ ee<smiles>O=S1(=O)N[C@](c2ccccc2)(c2ccc(Cl)cc2)c2ccccc21</smiles>

$90 \%, 97 \%$ ee<smiles>O=S1(=O)N[C@](c2ccc(F)cc2)(c2ccccc2O)c2ccccc21</smiles>

$81 \%, 99 \%$ ee<smiles>O=S1(=O)N[C@@](c2ccccc2)(c2ccc3ccccc3c2)c2ccccc2O1</smiles>

$84 \%, 99 \%$ ee

$\mathrm{ArB}(\mathrm{OH})_{2}$

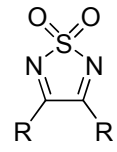

$\left[\mathrm{Rh}(\mathrm{coe})_{2} \mathrm{Cl}\right]_{2}(1.5 \mathrm{~mol} \%)$

$\mathrm{KF}(1.5 \mathrm{~mol} / \mathrm{L}), \mathrm{DCM}, 40{ }^{\circ} \mathrm{C}$

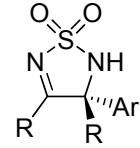<smiles>COc1ccc([C@]2(c3ccccc3)NS(=O)(=O)N=C2c2ccccc2)cc1</smiles>

$98 \%, 97 \%$ ee<smiles>O=S1(=O)N=C(c2ccccc2)[C@](c2ccccc2)(c2ccc(Cl)cc2)N1</smiles>

$91 \%, 99 \%$ ee

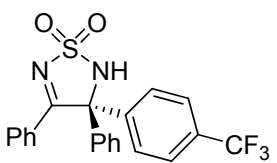

$91 \%, 99 \%$ ee

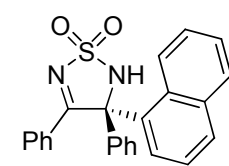

$94 \%, 99 \%$ ee

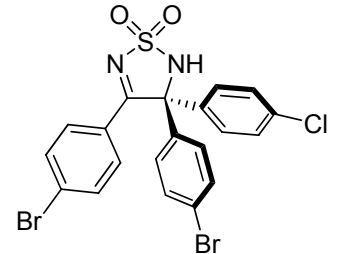

$84 \%, 99 \%$ ee

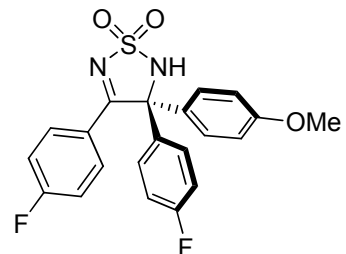

$99 \%, 96 \%$ ee

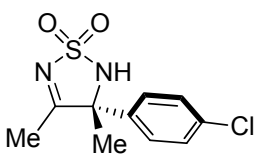

$70 \%, 96 \%$ ee
成了一系列 $\alpha$-位芳基和烷基取代的苯并磺内酰胺及苯 并磺胺内酯. 反应具有非常好的底物适用性, 可以取得 中等到优秀的收率, 尤其是产物的对映选择性可高达 99.9\% ee. 产物经简单转化, 可以进一步实现含季碳手 性中心的四氢异喹啉及苯并恶嗪酮类化合物的高效立 体选择性构建, 方法并首次实现了 NMDA 拮抗剂
FR115427 的催化不对称合成(Scheme 6).

随后，经过反应条件的微调，在相同的硫烯配体 $\mathbf{L} 16$ 促进下, $\mathrm{Xu}$ 等 ${ }^{[54]}$ 又实现了苯并噁嗪酮以及喹喔啉酮 的不对称芳基化反应，以极其优异的对映选择性(高达 $99.9 \% e e)$, 成功合成了一系列几乎光学纯的 3,4-二 氢-苯并 $[1,4]$-恶嗪-2-酮以及二氢喹喔啉酮类化合物(Eq. 
52).

$\alpha, \alpha$-二芳基氨基酸是一些具有重要生理活性的天然 产物、已上市药物及正在开发的活性化合物的关键核心 骨架, 然而其高效的不对称合成方法研究很少有成功的 报道. $\mathrm{Xu}$ 小组 ${ }^{[55]}$ 设计、发展了一类新型手性膦烯配体, 利用开链结构的 $\mathbf{L 2 1}$ 实现了铑催化下 1,2,5-噻二唑 啉-1,1-二氧类酮亚胺的不对称芳基化反应, 在温和的条 件下, 高效地合成了一系列含季碳手性的偕二芳基取代 的磺胺乙内酰艮以及 4-乙氧基-2,3-二氢-1,2,5-噻唑-1,1二氧类化合物(最高 $99 \%$ ee). 该方法操作简单、底物适 用范围广、立体选择性高, 产物经简单转化可用于非天 然的手性 $\alpha, \alpha$ 二芳基氨基酸衍生物的合成以及各种含氮 杂环的构建, 并首次实现了 Merck 公司报道的 BACE1 抑制剂 $(R)$-iminohydantoin 的催化不对称合成(Scheme 7).

最近, $\mathrm{Xu}$ 等 ${ }^{[56]}$ 又利用不同的烯烃配体, 实现了芳基 嗍酸对 $\alpha, \beta$-不饱和环状磺酰酮亚胺的分步 1,4-和 1,2-加
成反应，成功构建了高光学纯度的具有偕二芳基取代的 手性磺胺内酯, $C_{1}$-对称手性双烯配体 L7c 及手性硫烯配 体 L16 在反应中表现出很高的催化活性和对映选择性. 加成产物经简单转化后可以得到两类含季碳手性中心 并具有四并环结构的手性胺(Scheme 8).

一般来说, 对于一些稳定性差的亚胺很难进行直接 加成反应. 2013 年, Hayashi 和 Nishimura ${ }^{[57]}$ 以环状半缩 醛胺为起始反应物, 利用嗍酐的脱水作用在反应体系中 原位形成 $N$-羰基亚胺，实现了 $[\mathrm{Rh}(\mathrm{OH})(\mathbf{L 2 2 a})]_{2}$ 催化下 的高对映选择性不对称芳基加成( $91 \% \sim 98 \% e e)$, 用于 合成各种含有三芳基取代的立体中心的手性异吲哚啉 酮化合物(Scheme 9). 研究发现,选用高活性的着基铑络 合物作为催化剂是反应成功的关键，嗍酐在反应中既起 到脱水剂的作用，同时又是芳基加成试剂.

在进一步的研究中 ${ }^{[58]}$, 将上述发现的高活性的羟 基铑物种 $[\mathrm{Rh}(\mathrm{OH})(\mathbf{L 2 2} \mathbf{a})]_{2}$ 用于反应性相对略低的简单 环状磺酰亚胺的不对称芳基加成中，相比原位形成的催

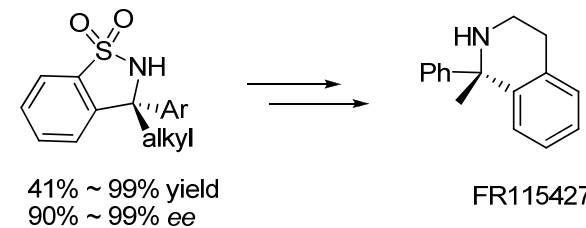

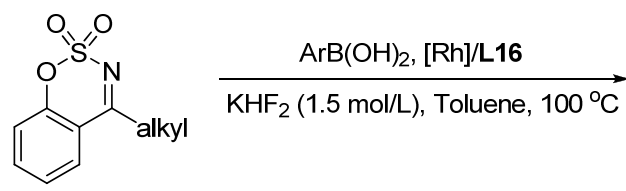

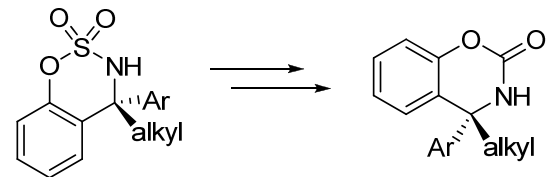

$17 \% \sim 96 \%$ yield

$97.6 \% \sim 99.9 \%$ ee

图式 6 环状 $N$-磺酰基取代烷基酮亚胺的不对称芳基化

Scheme 6 Asymmetric arylation of cyclic $N$-sulfonyl aryl alkyl ketimines

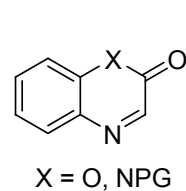

$X=O, N P G$
$(\mathrm{ArBO})_{3}$ $\underset{\text { dioxane, } \mathrm{K}_{3} \mathrm{PO}_{4} / \mathrm{MeOH}}{\stackrel{\left[\mathrm{Rh}(\mathrm{COE})_{2} \mathrm{Cl}\right]_{2} / \mathrm{L} 16}{\longrightarrow}}$ $60^{\circ} \mathrm{C}$<smiles>[X]C(=O)[C@H]([Al])Nc1ccccc1[X]</smiles>

$28 \% \sim 99 \%$ yield $95 \sim>99 \%$ ee

Selected examples:<smiles>Cc1ccccc1[C@H]1Nc2ccccc2OC1=O</smiles>

$99 \%, 99.7 \%$ ee<smiles>CN1C(=O)[C@@H](c2cccc3ccccc23)Nc2ccccc21</smiles>

$69 \%, 99.9 \%$ ee<smiles>O=C1Oc2ccccc2N[C@H]1c1ccsc1</smiles>

$99 \%, 99.9 \%$ ee<smiles>Cc1ccccc1[C@@H]1Nc2ccccc2N(C)C1=O</smiles>

$79 \%, 99.7 \%$ ee<smiles>O=C1Oc2ccc(Cl)cc2NC1c1ccccc1</smiles>

$98 \%, 99.7 \%$ ee<smiles>CN1C(=O)[C@H](c2ccccc2)Nc2cc(F)c(F)cc21</smiles>

$80 \%, 99.6 \%$ ee<smiles>O=C1Oc2ccccc2NC1/C=C/c1ccccc1</smiles>

$28 \%, 95 \%$ ee<smiles>COc1ccc([C@@H]2Nc3ccccc3N(Cc3ccccc3)C2=O)cc1</smiles>

$69 \%, 98.9 \%$ ee 


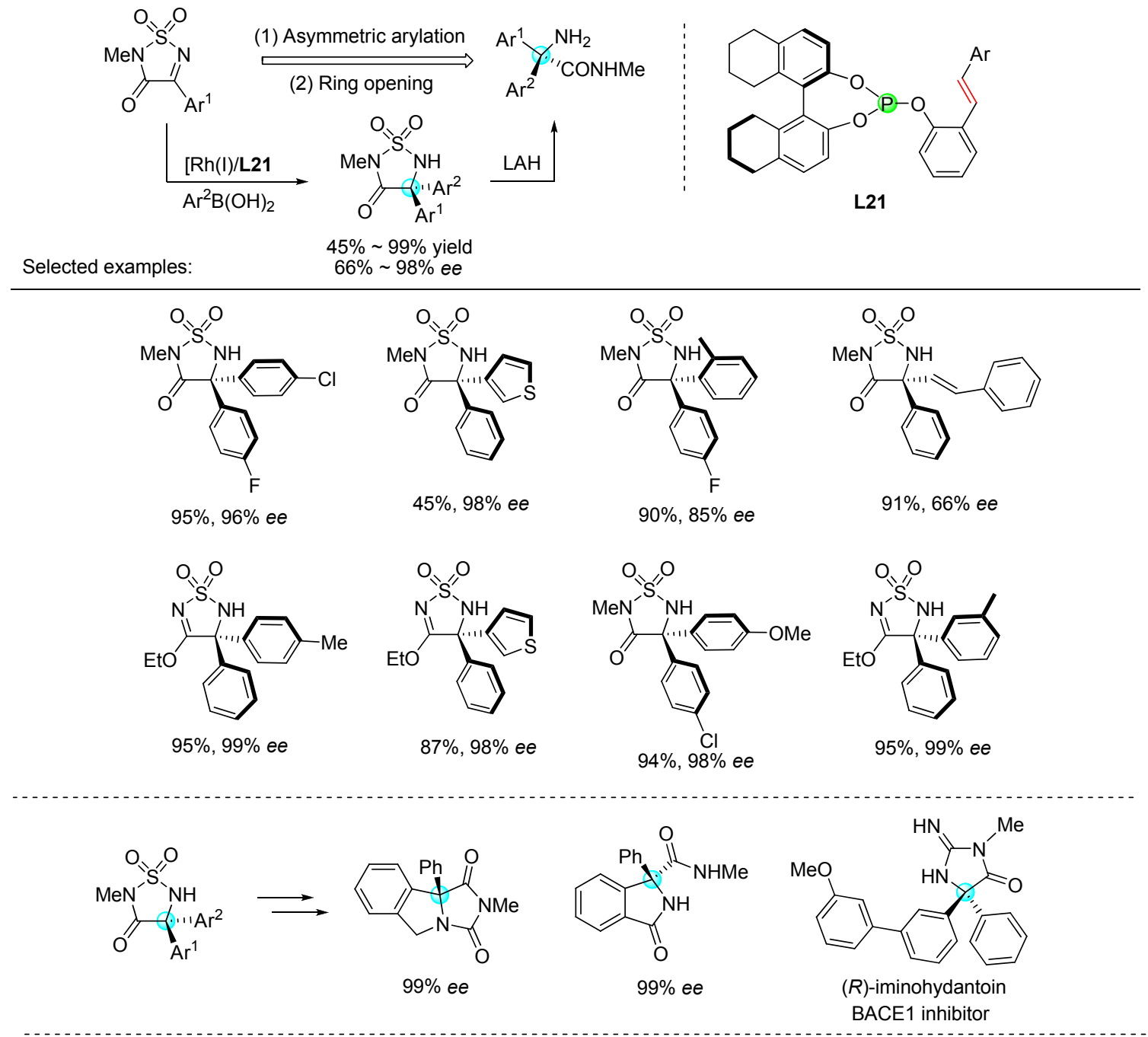

图式 7 简单手性膦-烯配体用于环状亚胺的不对称芳基化

Scheme 7 Simple phosphite-olefin as ligand for asymmetric arylation of cyclic ketimine

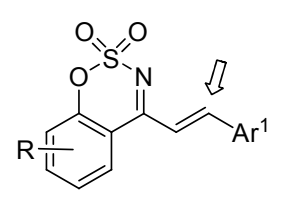

Selected examples:

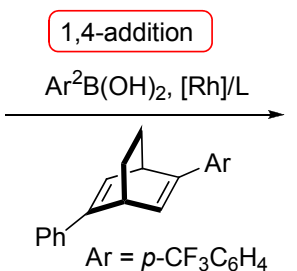

L7c

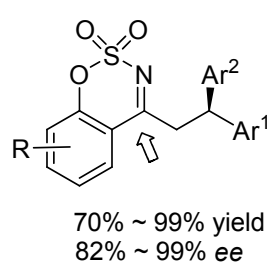

$82 \% \sim 99 \%$ ee

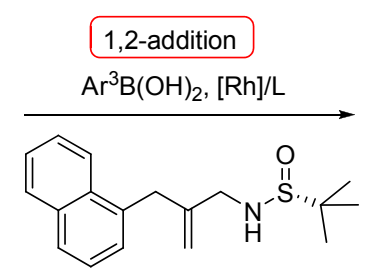

L16

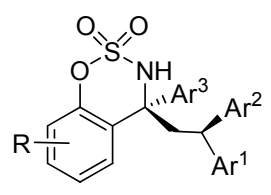

up to $83 \%$ yield up to $99 \%$ ee

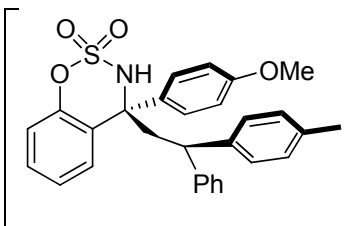

$99.5 \%$ de

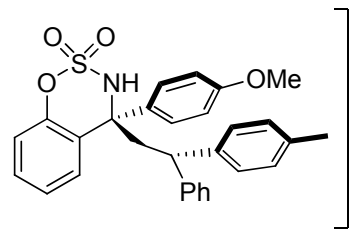

$93 \%$ de

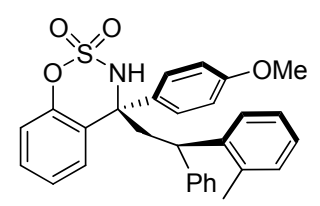

$68 \%, 99 \%$ ee

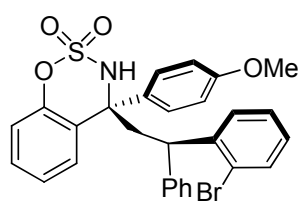

$62 \%, 99 \%$ ee

图式 8 铑催化的 $\alpha, \beta$-不饱和环状酮亚胺的逐步不对称 1,4-和 1,2-加成

Scheme 8 Rh-catalyzed stepwise asymmetric 1,4- and 1,2-addition of $\alpha, \beta$-unsaturated cyclic ketimines 


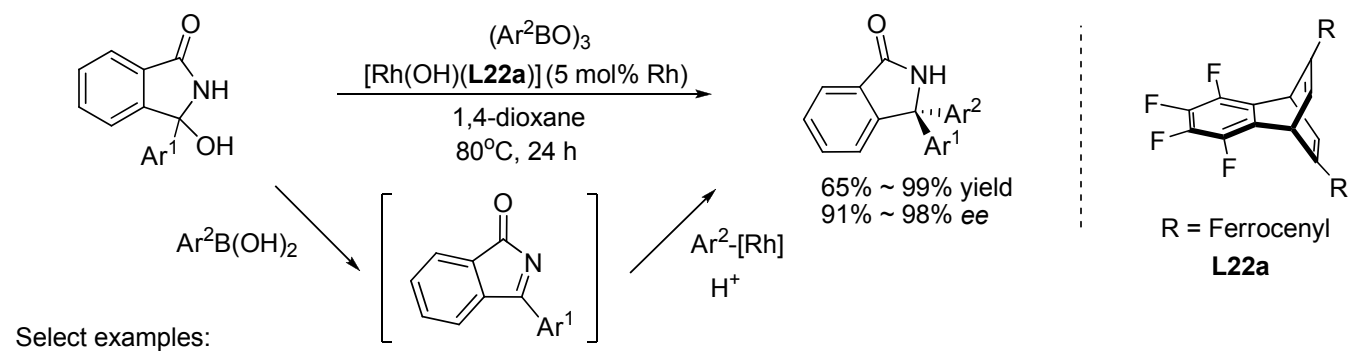

Select examples:

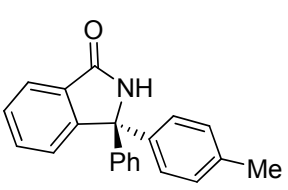

$98 \%, 95 \%$ ee<smiles>O=C1NC(c2ccccc2)(c2ccccc2)c2ccccc21</smiles>

$91 \%, 97 \%$ ee<smiles>O=C1NC(c2ccccc2)(c2ccc(C(F)(F)F)cc2)c2ccccc21</smiles>

$96 \%, 97 \%$ ee

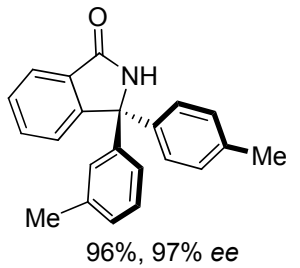

$96 \%, 97 \%$ ee<smiles>Cc1ccc(C2(c3ccco3)NC(=O)c3ccccc32)cc1</smiles>

$87 \%, 96 \%$ ee<smiles>Cc1ccc(C2(c3ccccc3)NC(=O)c3ccccc32)cc1</smiles>

$89 \%, 93 \%$ ee

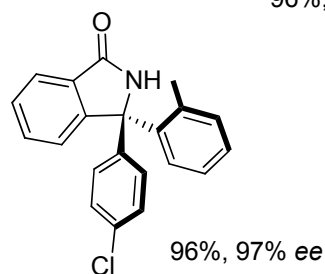

图式 9 3-芳基-3-羊基-1-异吲哚啉酮的不对称芳基化

Scheme 9 Asymmetric arylation of 3-aryl-3-hydroxyisoindolin-1-ones

化剂，反应可以取得明显提高的收率(70\% 98\%) 以及 优异的对映选择性(91\% 99\% ee) (Eq. 53). 所得产物 $\alpha$ 二芳基磺胺内酯经过几步简单转化可以在 $e e$ 值保持的 情况下开环得到各种含季碳手性的胺类合成砌块.

类似的, Lin, Feng 等 ${ }^{[59}$ 基于双环 [3.3.0]手性双烯配 体 L10, 将活性羟基铑物种 $[\mathrm{Rh}(\mathrm{OH})(\mathbf{L 1 0})]_{2}$ 用于催化环 状磺酰脂肪酮亚胺的对映选择性芳基化反应, 实现了一 系列含四取代手性中心的磺胺内酯类化合物的高效不 对称合成, 最高取得 $98 \%$ ee (Eq. 54). 研究发现选择更 加稳定的芳基频那醇嗍酯作为嗍试剂可以相应减少脱 嗍副反应, 从而提高反应收率, 但当缺电子的芳基嗍酯 参与反应时, 收率仍有急剧的下降, 且亚胺底物中的烷 基取代基的位阻也会对反应收率有明显的影响. 同样, 产物在 LAH 的条件下开环, 可以得到光学活性的 $\beta$-氨<smiles>[X]S(=O)(=O)I</smiles><smiles>O=S1(=O)CCC=N1</smiles>
$\mathrm{X}=\mathrm{CH}_{2}, \mathrm{O}, \mathrm{NPG}$<smiles>CC1(C)COB([Al])OC1</smiles>

$[\mathrm{Rh}(\mathrm{OH})(\mathrm{L22a})]_{2}$

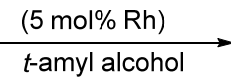

toluene, $60^{\circ} \mathrm{C}, 20 \mathrm{~h}$

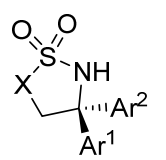

$70 \% \sim 98 \%$ yield 91\% 99\% ee
2015 年, Nishimura 等 ${ }^{[60]}$ 又报道了活性羟基铑物种 $[\mathrm{Rh}(\mathrm{OH})(\mathbf{L 2 2 b})]_{2}$ 催化环状磺酰亚胺酯的不对称芳基化 反应，实现了一系列手性偕二芳基取代的苯并磺胺内酯 类化合物的高效合成，取得了 $83 \% \sim 97 \%$ ee (Eq. 55). 产物可以经简单转化, 以中等收率得到 $e e$ 值保持的 $\alpha, \alpha-$ 二芳基- $\alpha$ - $N$-甲基氨基酸酯.

\subsection{3 手性含氮配体}

2013 年, Zhang 小组 ${ }^{[61]}$ 报道了首例二价钯催化下, 吡啶-噁唑啉配体 L23 促进的环状脂肪酮亚胺的不对称 芳基化反应. 反应在空气条件下进行，以利于将生成的 $\mathrm{Pd}^{0}$ 氧化成 $\mathrm{Pd}^{\mathrm{II}}$, 同时选用极性的三氟乙醇为溶剂以帮 助加快质子化步骤, 从而提高收率(Eq. 56). 反应的底物

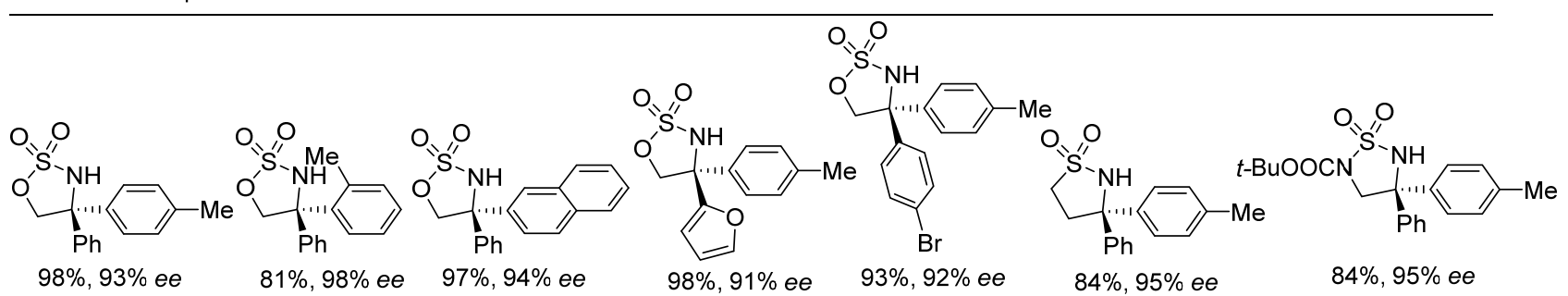



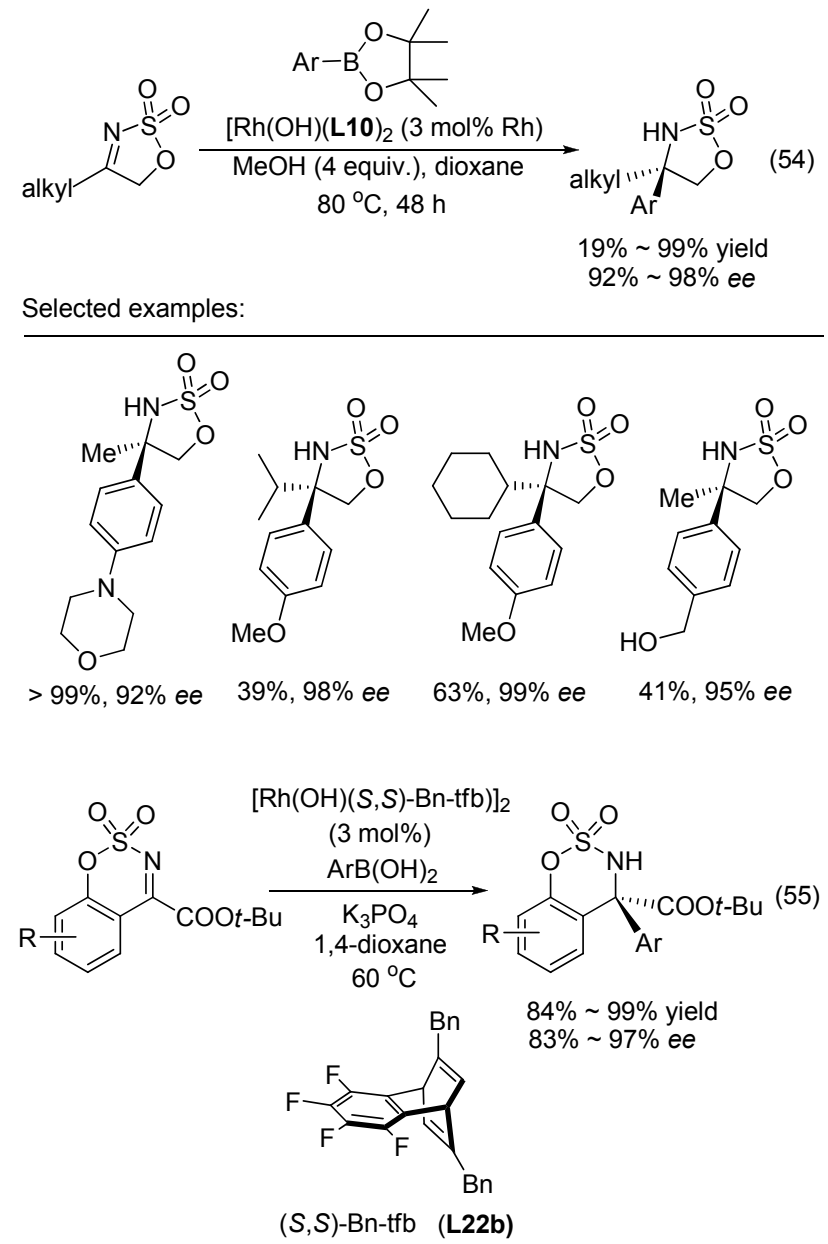

Selected examples:

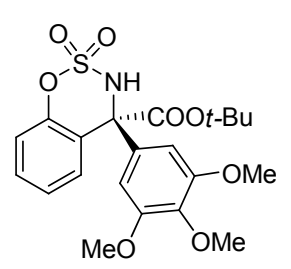

$94 \%, 86 \%$ ee<smiles>CCCOC(=O)[C@]1(c2ccc(C)cc2)NS(=O)(=O)Oc2c(C)cccc21</smiles>

$94 \%, 94 \%$ ee

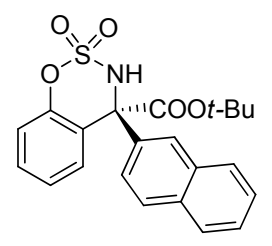

$96 \%, 95 \%$ ee

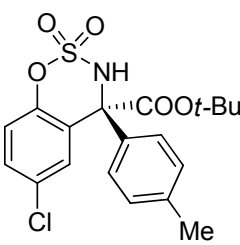

$99 \%, 84 \%$ ee
适应性较好, 吸电子硼酸也能取得较高的收率, 但芳基 邻位有取代的硼酸对反应收率和选择性有明显的影响, 当选用 2-甲氧基苯硼酸时反应在 $48 \mathrm{~h}$ 后也仅有约 $15 \%$ 的核磁收率.

反应的立体选择性可以通过如下模型来解释(Eq. 57), 转金属化后的钯物种中, 芳基处于噁唑啉环的对 位, 而亚胺则从吡啶环的对位与铑配位, 为避免环上

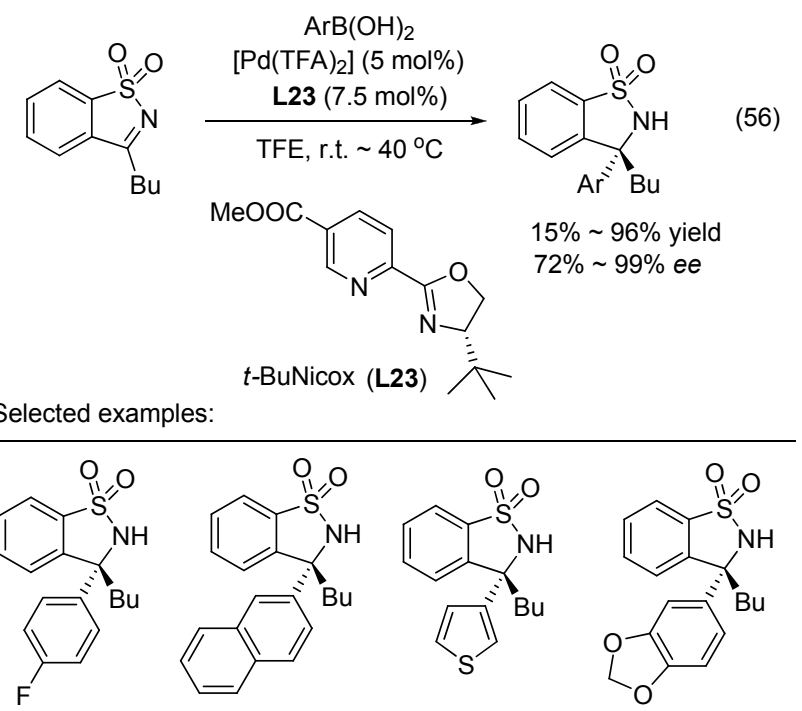

$99 \%, 94 \%$ ee $\quad 74 \%, 96 \%$ ee $\quad 89 \%, 90 \%$ ee

$99 \%, 93 \%$ ee

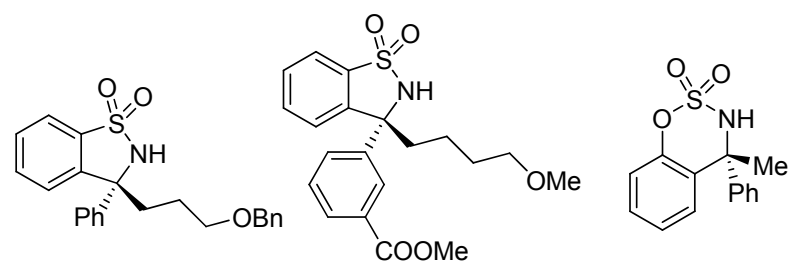

$99 \%, 96 \%$ ee

$90 \%, 93 \%$ ee

$58 \%, 95 \%$ ee

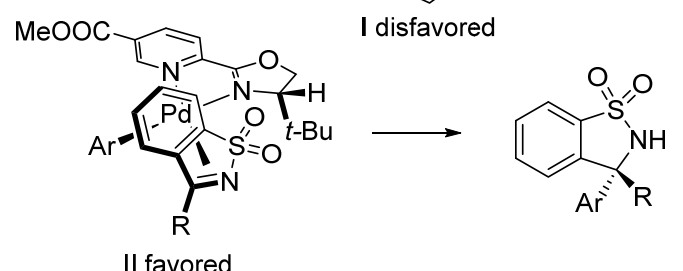

$\mathrm{SO}_{2}$ 基团与配体中的叔丁基的位阻，主要采取过渡态 II 中的取向, $\mathrm{Ar}$ 从亚胺的 $R e$ 面进攻, 得到相应构型的产 物.

2014 年, Lu, Hayashi 等 ${ }^{[62]}$ 也报道了钯催化的环状酮 亚胺的不对称芳基化. 相比五元环系底物，六元环状亚 胺的反应性通常要低, 但加成产物却更容易经开环得到 各种衍生物. 对多种手性配体包括膦-噁唑啉、吡啶-啞 唑啉、双膦、双烯等的考察结果表明，手性膦-噁唑啉配 体 $i$-Pr-Phox 可以给出最好的反应结果. 值得一提的是, 反应条件中添加物 $\mathrm{AgBF}_{4}, \mathrm{AgSbF}_{6}, \mathrm{~K}_{3} \mathrm{PO}_{4}$ 及质子海绵的 选择对收率和选择性非常关键，一些情况下产物会发生 消旋化，因此还需要 $\mathrm{AgBF}_{4}$ 或 $\mathrm{AgSbF}_{6}$ 与碱性的 $\mathrm{K}_{3} \mathrm{PO}_{4}$ 或质子海绵的组合以中和反应体系中的酸性. 在各自的 
最优反应条件下，反应大都可以取得很高的收率和极其 优秀的对映选择性(96\% 99.9\% ee) (Eq. 58).

2015 年, Zhang, Xie 等 ${ }^{[63]}$ 又报道了二价钯催化下吡 啶-恶唑啉配体 L23 促进的环状磺酰亚胺酯的不对称芳 基化反应. 催化体系能实现优异的立体选择性控制 (95\% 99\% ee), 但对于大位阻芳基砋酸、杂芳基喼酸及 带有吸电子基团的芳基嗍酸反应收率会有不同程度的 下降. DFT 计算表明反应中芳基插入亚胺的一步是反应 的决速步，也是选择性控制的关键步(Eq. 59).

在一系列钯催化的不对称芳基加成研究取得突破 之后, Lassaletta, Fernández, Monge 等 ${ }^{[64]}$ 进一步设计了一 类新型的手性吡啶一腙配体, 也成功应用于之前报道的 各种环状磺酰酮亚胺，包括芳香亚胺、脂肪亚胺、酯基 取代亚胺及磺酰二酮亚胺等的不对称芳基化反应中, 取 得了优良的收率和对映选择性(Eqs. 60, 61).

虽然过渡金属催化的酮亚胺的不对称加成近年来
取得了很大的进展，但是吲哚酮亚胺却一直是一类非常 挑战的底物，利用芳基硼试剂对其进行加成此前并未有 成功的报道. 最近, Zhang 小组 ${ }^{[65]}$ 通过对底物中吲哚和 亚胺氮上的保护基的详细考察以及系列手性吡啶-恶唑 啉配体的笁选，实现了钯催化下芳基硼酸对该类底物的 不对称加成反应. 研究发现, In-Pyrox 为最优配体, 当底 物分子中吲哚和亚胺氮上分别为 2,6-二氯苄基和叔丁基 磺酰基时，在三氟乙醇溶剂中，70 ${ }^{\circ} \mathrm{C}$ 条件下，反应可以 取得了 $90 \% \sim 98 \%$ ee (Eq. 62).

\section{3 总结与展望}

由于 $\alpha$-手性胺在有机合成及药物研究中的重要用 途，化学家们对它们的不对称合成方法的探索乐此不 疲. 综上所述，基于手性辅剂及手性配体策略的过渡金 属催化的有机嗍试剂对亚胺的不对称加成研究在近十<smiles>[R]C1=NS(=O)(=O)Oc2ccccc21</smiles>

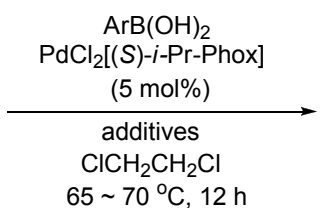

Addtive: $\mathrm{AgSbF}_{6} / \mathrm{K}_{3} \mathrm{PO}_{4}$ or $\mathrm{AgSbF}_{6} /$ proton sponge

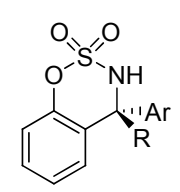

$48 \% \sim 99 \%$ yield $96 \% \sim 99.9 \%$ ee Selected examples:

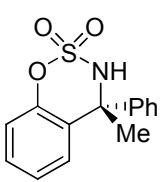

$99 \%, 99.5 \%$ ee

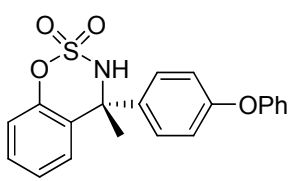

$99 \%, 98.6 \%$ ee

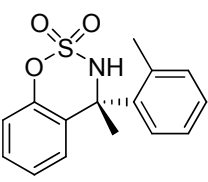

$51 \%, 99.9 \%$ ee

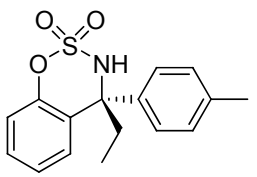

$51 \%, 99.9 \%$ ee

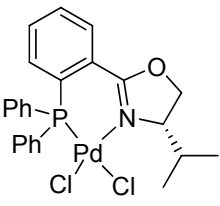

$\mathrm{PdCl}_{2}[(S)-i-\mathrm{Pr}-\mathrm{Phox}]$

L24

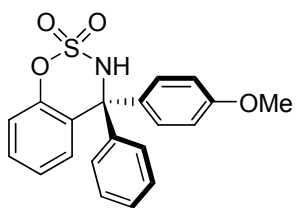

$65 \%, 99.6 \%$ ee

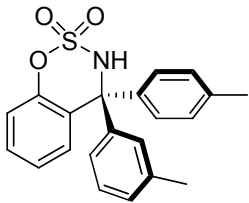

$68 \%, 97 \%$ ee<smiles>COC(=O)C1=NS(=O)(=O)Oc2c[c][14cH]cc21</smiles>

$$
\begin{aligned}
& \left.\underset{\operatorname{Pd}(\mathrm{TFA})_{2}(5 \mathrm{~mol} \%)}{\operatorname{L23}(7.5 \mathrm{~mol} \%)}\right) \\
& \operatorname{ArB}(\mathrm{OH})_{2} \\
& \text { TFE, } 60^{\circ} \mathrm{C}, 24 \sim 36 \mathrm{~h}
\end{aligned}
$$

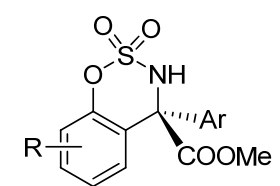

$52 \% \sim 99 \%$ yield $95 \% \sim 99 \%$ ee

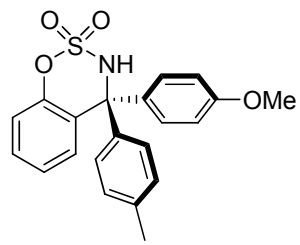

$80 \%, 99.2 \%$ ee

Selected examples:

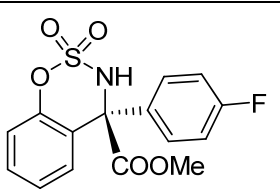

$90 \%, 98 \%$ ee

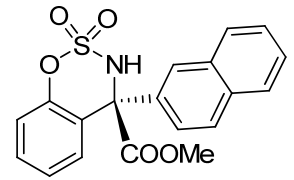

$74 \%, 99 \%$ ee

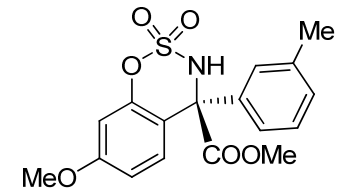

$98 \%, 97 \%$ ee
MeOOC<smiles>CC(C)(C)[13CH3]</smiles>
L23 

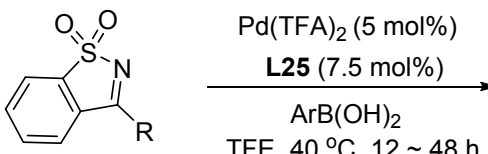

TFE, $40^{\circ} \mathrm{C}, 12 \sim 48 \mathrm{~h}$

$\mathrm{R}=\mathrm{Aryl}, \mathrm{Me}, \mathrm{Et}, \mathrm{COOE}$<smiles>O=[13C]C1[C@H](c2ccccc2)CC[C@H]1c1ccccn1</smiles>
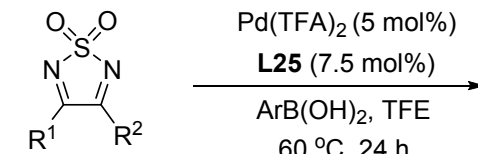

$\mathrm{R}^{1}, \mathrm{R}^{2}=\mathrm{Ph}, \mathrm{Me}$

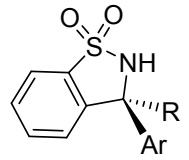

$70 \% \sim 99 \%$ yield $86 \% \sim 97 \%$ ee

等. 值得一提的是，在铑催化的反应中，手性烯烃类配 体展现出尤为独特的催化活性和对映选择性，而且部分 如手性硫烯，结构极其简单、合成方便，令人印象深刻， 为一些重要手性胺及相关生理活性分子的合成提供了 温和、高效并相对经济的方法. 另一方面, 近年来发展 起来的基于含氮配体的钯催化反应也非常值得关注，但 目前在研究的深度和广度上还有待于进一步探索. 相对 于金属铑和钯，其它廉价过渡金属如铜、镍等催化的有 机嗍试剂对亚胺的不对称加成研究仍未有突破. 在今后 的研究中, 设计简单高效的新型手性配体, 开发实用的 催化体系, 拓展结构新颖的反应底物, 探索多样性的有 机硼试剂, 仍然充满着挑战和机遇. 随着人们对相关反 应的不对称催化机理的理解和认识的不断深入, 相信这 个领域的研究必将取得更大的发展.

\section{Referenes}

[1] (a) Calderon, S. N.; Rothman, R. B.; Porreca, F.; Flippen-Anderson, J. L.; McNutt, R. W.; Xu, H.; Smith, L. E.; Bilsky, E. J.; Davis, P.; Rice, K. C. J. Med. Chem. 1994, 37, 2125.

(b) Van Bambeke, F.; Van Laethem, Y.; Courvalin, P.; Tulkens, P. M. Drugs 2004, 64, 913.

(c) Calderon, S. N.; Rice, K. C.; Rothman, R. B.; Porreca, F.; Anderson, J. L. F.; Kayakiri, H.; Xu, H.; Becketts, K.; Smith, L. E.; Bilsky, E. J.; Davis, P.; Horvath, R. J. Med. Chem. 1997, 40, 695.

(d) Wiseman, L. R.; Benfield, P. Drugs 1993, 2, 295.

[2] (a) Deng, Q. H.; Xu, H. W.; Yuen, A. W.; Xu, Z. J.; Che, C. M. Org. Lett. 2008, 10, 1529 .

(b) Lee, E. C.; Fu, G. C. J. Am. Chem. Soc. 2007, 129, 12066.

(c) Xu, B.; Zhu, S. F.; Zuo, X. D.; Zhang, Z. C.; Zhou, Q. L. Angew. Chem., Int. Ed. 2014, 53, 3913.

(d) Xu, B.; Zhu, S. F.; Xie, X. L.; Shen, J. J.; Zhou, Q. L. Angew. Chem., Int. Ed. 2011, 50, 11483.

[3] (a) Tang, W.; Zhang, X. Chem. Rev. 2003, 103, 3029.

(b) Kobayashi, S.; Ishitani, H. Chem. Rev. 1999, 99, 1069.

(c) Wang, D. S.; Chen, Q. A.; Lu, S. M.; Zhou, Y. G. Chem. Rev. 2012, 112, 2557.

[4] (a) Wang, J.; Liu, X.; Feng, X. Chem. Rev. 2011, 111, 6947.

(b) Kobayashi, S.; Mori, Y.; Fossey, J. S.; Salter, M. M. Chem. Rev. 2011, 111, 2626.

(c) Marques, C. S.; Burke, A. J. Chem CatChem 2011, 3, 635.

(d) Robak, M. T.; Herbage, M. A.; Ellman, J. A. Chem. Rev. 2010, 110,3600 .

(e) Lin, G.-Q.; Xu, M.-H.; Zhong, Y.-W.; Sun, X.-W. Acc. Chem. Res. 2008, 41,831 .

(f) Ellman, J. A.; Owens, T. D.; Tang, T. P. Acc. Chem. Res. 2002, 35,984

[5] (a) Suzuki, A. J. Organo. Chem. 1999, 576, 147.

(b) Miyaura, N. Cross-Coupling Reactions. A Practical Guide, Topics in Current Chemistry, Vol. 219, Springer, Berlin, 2002.

(c) Negishi, E. Handbook of Organopalladium Chemistry for Organic Synthesis, Vol. 1, Wiley, New York, 2002.

(d) Liu, Q; Tian, B.; Tian, P.; Tong, X.-F.; Lin, G.-Q. Chin. J. Org. Chem. 2015, 35, 1 (in Chinese).

(刘强, 田兵, 田平, 童晓峰, 林国强, 有机化学, 2015, 35, 1.)

(e) Liu, Y.-Y.; Zhang, W.-B. Chin. J. Org. Chem. 2016, 36, 2249 (in Chinese).

(刘媛媛，张万斌，有机化学，2016, 36, 2249.)

[6] Weix, D. J.; Shi, Y.; Ellman, J. A. J. Am. Chem. Soc. 2005, 127, 1092.

[7] Bolshan, Y.; Batey, R. A. Org. Lett. 2005, 7, 1481. 
[8] Beenen, M. A.; Weix, D. J.; Ellman, J. A. J. Am. Chem. Soc. 2006, $128,6304$.

[9] Brak, K.; Ellman, J. A. J. Am. Chem. Soc. 2009, 131, 3850.

[10] Brak, K.; Ellman, J. A. J. Org. Chem. 2010, 75, 3147.

[11] Brak, K.; Ellman, J. A. Org. Lett. 2010, 12, 2004.

[12] Dai, H.; Lu, X. Org. Lett. 2007, 9, 3077.

[13] Kuriyama, M.; Soeta, T.; Hao, X.; Chen, Q.; Tomioka, K. J. Am. Chem. Soc. 2004, 126, 8128.

[14] Hao, X.; Kuriyama, M.; Chen, Q.; Yamamoto, Y.; Yamada, K.; Tomioka, K. Org. Lett. 2009, 11, 4470.

[15] Hao, X.; Chen, Q.; Yamada, K.-i.; Yamamoto, Y.; Tomioka, K. Tetrahedron 2011, 67, 6469.

[16] Hao, X.; Chen, Q.; Kuriyama, M.; Yamada, K.-I.; Yamamoto, Y.; Tomioka, K. Cat. Sci. Tec. 2011, 1, 62 .

[17] Trincado, M.; Ellman, J. A. Angew. Chem., Int. Ed. 2008, 47, 5623.

[18] Jagt, R. B.; Toullec, P. Y.; Geerdink, D.; de Vries, J. G.; Feringa, B. L.; Minnaard, A. J. Angew. Chem., Int. Ed. 2006, 45, 2789.

[19] Duan, H.-F.; Jia, Y.-X.; Wang, L.-X.; Zhou, Q.-L. Org. Lett. 2006, $8,2567$.

[20] Kurihara, K.; Yamamoto, Y.; Miyaura, N. Adv. Synth. Catal. 2009, $351,260$.

[21] Lee, A.; Kim, H. J. Org. Chem. 2016, 81, 3520.

[22] Tokunaga, N.; Otomaru, Y.; Okamoto, K.; Ueyama, K.; Shintani, R.; Hayashi, T. J. Am. Chem. Soc. 2004, 126, 13584.

[23] Otomaru, Y.; Kina, A.; Shintani, R.; Hayashi, T. Tetrahedron: Asymmetry 2005, 16, 1673.

[24] Okamoto, K.; Hayashi, T.; Rawal, V. H. Chem. Commun. 2009, 4815.

[25] Crampton, R.; Woodward, S.; Fox, M. Adv. Synth. Catal. 2011, 353, 903.

[26] Crampton, R. H.; Fox, M.; Woodward, S. Tetrahedron: Asymmetry 2013, 24, 599 .

[27] Fujioka, M.; Morimoto, T.; Tsumagari, T.; Tanimoto, H.; Nishiyama, Y.; Kakiuchi, K. J. Org. Chem. 2012, 77, 2911.

[28] Wang, Z.-Q.; Feng, C.-G.; Xu, M.-H.; Lin, G.-Q. J. Am. Chem. Soc. 2007, 129, 5336.

[29] Wang, Z.-Q.; Feng, C.-G.; Zhang, S.-S.; Xu, M.-H.; Lin, G.-Q. Angew. Chem., Int. Ed. 2010, 49, 5780 .

[30] Wang, L.; Wang, Z.-Q.; Xu, M.-H.; Lin, G.-Q. Synthesis 2010, 3263.

[31] Yang, H.-Y.; Xu, M.-H. Chem. Commun. 2010, 46, 9223.

[32] Shao, C.; Yu, H.-J.; Wu, N.-Y.; Feng, C.-G.; Lin, G.-Q. Org. Lett. 2010, 12, 3820 .

[33] Cui, Z.; Yu, H.-J.; Yang, R.-F.; Gao, W.-Y.; Feng, C.-G.; Lin, G.-Q. J. Am. Chem. Soc. 2011, 133, 12394.

[34] Cao, Z.; Du, H. Org. Lett. 2010, 12, 2602.

[35] Chen, C.-C.; Gopula, B.; Syu, J.-F.; Pan, J.-H.; Kuo, T.-S.; Wu, P.-Y.; Henschke, J. P.; Wu, H.-L. J. Org. Chem. 2014, 79, 8077.

[36] Luo, Y.; Carnell, A. J.; Lam, H. W. Angew. Chem., Int. Ed. 2012, 51,6762 .
[37] Luo, Y.; Hepburn, H. B.; Chotsaeng, N.; Lam, H. W. Angew. Chem., Int. Ed. 2012, 51, 8309.

[38] Cui, Z.; Chen, Y.-J.; Gao, W.-Y.; Feng, C.-G.; Lin, G.-Q. Org. Lett. 2014, 16, 1016.

[39] Gopula, B.; Chiang, C. W.; Lee, W. Z.; Kuo, T. S.; Wu, P. Y.; Henschke, J. P.; Wu, H. L. Org. Lett. 2014, 16, 632.

[40] Shintani, R.; Narui, R.; Tsutsumi, Y.; Hayashi, S.; Hayashi, T. Chem. Commun. 2011, 47, 6123.

[41] Wang, H.; Xu, M.-H. Synthesis 2013, 45, 2125.

[42] Jiang, T.; Chen, W.-W.; Xu, M.-H. Org. Lett. 2017, 19, 2138.

[43] Chen, J.; Lu, X.; Lou, W.; Ye, Y.; Jiang, H.; Zeng, W. J. Org. Chem. 2012, 77, 8541.

[44] Jung, H. H.; Buesking, A. W.; Ellman, J. A. Org. Lett. 2011, 13, 3912.

[45] Wada, R.; Shibuguchi, T.; Makino, S.; Oisaki, K.; Kanai, M.; Shibasaki, M. J. Am. Chem. Soc. 2006, 128, 7687.

[46] Osborne, C. A.; Endean, T. B. D.; Jarvo, E. R. Org. Lett. 2015, 17, 5340 .

[47] Kong, J.; McLaughlin, M.; Belyk, K.; Mondschein, R. Org. Lett. 2015, 17, 5520 .

[48] Shintani, R.; Takeda, M.; Tsuji, T.; Hayashi, T. J. Am. Chem. Soc. 2010, 132, 13168.

[49] Shintani, R.; Takeda, M.; Soh, Y. T.; Ito, T.; Hayashi, T. Org. Lett. 2011, 13, 2977.

[50] Nishimura, T.; Noishiki, A.; Tsui, G. C.; Hayashi, T. J. Am. Chem. Soc. 2012, 134, 5056.

[51] Wang, H.; Jiang, T.; Xu, M.-H. J. Am. Chem. Soc. 2013, 135, 971.

[52] Wang, H.; Li, Y.; Xu, M.-H. Org. Lett. 2014, 16, 3962.

[53] Jiang, T.; Wang, Z.; Xu, M.-H. Org. Lett. 2015, 17, 528.

[54] Zhang, X.; Xu, B.; Xu, M.-H. Org. Chem. Front. 2016, 3, 944.

[55] Li, Y.; Yu, Y.-N.; Xu, M.-H. ACS Catal. 2016, 6, 661.

[56] Zhang, Y.-F.; Chen, D.; Chen, W.-W.; Xu, M.-H. Org. Lett. 2016, $18,2726$.

[57] Nishimura, T.; Noishiki, A.; Ebe, Y.; Hayashi, T. Angew. Chem., Int. Ed. 2013, 52, 1777.

[58] Nishimura, T.; Ebe, Y.; Fujimoto, H.; Hayashi, T. Chem. Commun. 2013, 49, 5504.

[59] Chen, Y.-J.; Chen, Y.-H.; Feng, C.-G.; Lin, G.-Q. Org. Lett. 2014, 16,3400 .

[60] Takechi, R.; Nishimura, T. Org. Biomol. Chem. 2015, 13, 4918.

[61] Yang, G.; Zhang, W. Angew. Chem., Int. Ed. 2013, 52, 7540.

[62] Jiang, C.; Lu, Y.; Hayashi, T. Angew. Chem., Int. Ed. 2014, 53, 9936.

[63] Quan, M.; Yang, G.; Xie, F.; Gridnev, I. D.; Zhang, W. Org. Chem. Front. 2015, 2, 398.

[64] Álvarez-Casao, Y.; Monge, D.; Álvarez, E.; Álvarez, E.; Fernández, Lassaletta, J. M. Org. Lett. 2015, 17, 5104.

[65] He, Q.; Wu, L.; Kou, X.; Butt, N.; Yang, G.; Zhang, W. Org. Lett. 2016, 18, 288. 